\title{
Investigation of organo-carbonate associations in carbonaceous chondrites by Raman
}

\section{spectroscopy}

Queenie H. S. Chan ${ }^{\mathrm{a}, *}$, Michael E. Zolensky ${ }^{\mathrm{a}}$, Robert. J. Bodnar ${ }^{\mathrm{b}}$, Charles Farley ${ }^{\mathrm{b}}$, and Jacob C. H. Cheung ${ }^{c}$

${ }^{a}$ NASA Johnson Space Center, Houston, Texas 77058, USA

${ }^{\mathrm{b}}$ Department of Geosciences, Virginia Tech, Blacksburg, VA 24061, USA

${ }^{c}$ Met Office, Exeter, UK

* Correspondence to: Queenie H. S. Chan. Correspondence and requests for materials should be addressed to Q.H.S.C. (Email: hschan@ nasa.gov; Telephone: +1 (281) 483-4143)

\begin{abstract}
Carbonates record information regarding the timing, nature and conditions of the fluids circulating through asteroid parent bodies during aqueous alteration events. Determining carbonate abundances and their relationships with organic matter improves our understanding of the genesis of major carbonaceous components in chondritic materials. In this study, five CM2 carbonaceous chondrites (CM2.2 Nogoya, CM2.3 Jbilet Winselwan, CM2.5 Murchison, CM2 Santa Cruz, and CM2TII Wisconsin Range 91600) were studied with Raman spectroscopy. Carbonates were identified in these meteorite samples by the distinctive Raman band in the $\sim 1100 \mathrm{~cm}^{-1}$ region, representing the symmetric stretching vibration mode $\left(v_{1}\right)$ of the $\left(\mathrm{CO}_{3}\right)^{2-}$ anion. Carbonates identified in the meteorite samples are all calcite, with the exception of a single dolomite grain in Nogoya. The $v_{1}$ positions of the CM calcites are 2-3 $\mathrm{cm}^{-1}$ higher than in pure calcite, which suggests that they contain significant impurity cations. Typical graphitic first-order D and G bands were identified in the meteorite matrix as well as in $\sim 25 \%$ of the analyzed carbonate grains. From the Raman results, we postulate that the carbonates might not have formed under equilibrium conditions from a single fluid. The first
\end{abstract} 1 
generation of carbonate is interpreted to have formed from highly oxidized fluids that led to the oxidation of organic matter $(\mathrm{OM})$ and produced carbonates that are OM-barren. The second generation of carbonate was formed from a more evolved aqueous fluid with the presence of OM. The Raman parameters of the organics in carbonates clearly deviate from the matrix OM which suggests that the carbonate organics contain very different carbonaceous components that are distinct from the typical amorphous $\mathrm{OM}$ of the $\mathrm{CM}$ matrix. The occurrence of different generations of carbonate in close proximity may be partly responsible for the wide range in estimated ages of carbonates in carbonaceous chondrites reported in previous studies.

\section{KEYWORDS}

Organic matter, Raman spectroscopy, carbonates, carbonaceous chondrites, aqueous alteration, thermal metamorphism

\section{INTRODUCTION}

Carbonaceous chondrites are primitive meteorites that contain a large variety of carbon- and nitrogen-bearing compounds that have been widely investigated to better understand abiotic chemical processes. Although carbonate materials make up less than 3 vol\% of $\mathrm{CM}$ chondrites (Johnson and Prinz, 1993; Zolensky et al., 1997; de Leuw et al., 2010), they comprise the second most abundant class of carbon-bearing phases in these meteorites after organic matter, followed by other $\mathrm{C}$-bearing phases such as diamond, silicon carbide, and graphite (Smith and Kaplan, 1970; Sephton et al., 2003). Therefore, understanding the abundances of carbonates and the associated organic matter provides critical insight into the genesis of major carbonaceous components in chondritic materials. 
Carbonate materials contain the oxidized form of carbon. They have been widely studied in meteorites as their presence can shed light on the origin and distribution of biologically relevant compounds such as water and carbon dioxide on planetary and asteroid parent bodies. Carbonates in carbonaceous chondrites were originally proposed to be nebular products by Lancet and Anders (1970). More recently, they have been interpreted to be either the result of late-stage alteration and leaching of matrix silicates by aqueous solutions circulating through primitive bodies (e.g., McSween, 1979; Bunch and Chang, 1980; Fredriksson and Kerridge, 1988; Grady et al., 1988), melting of ice in situ, vapor diffusion through fractures (e.g., Grimm and McSween, 1989), or crystallization from shock-melted material (e.g., Scott et al., 1997). It has also been suggested that they formed very early in solar system history, possibly contemporaneously with parent body formation (Macdougall et al., 1984). Other than samples that demonstrate a shock history, carbonates record information regarding the timing, nature and conditions (e.g. temperature) of the aqueous fluids and events associated with their formation.

Carbonates in CM chondrites mostly occur as calcite (of varying composition) and dolomite (e.g., Johnson and Prinz, 1993; Zolensky et al., 1997; de Leuw et al., 2010; Lee et al., 2014). The chemistry, occurrence and abundance of carbonates in CM chondrites are not uniform. While carbonates are exclusively calcite in CM2 Elephant Moraine (EET) 90047, both calcite and dolomite are found in CM2 Allan Hills (ALH) 83100 and CM1 EET 83334. Carbonates occur in the cores of altered chondrules in ALH 83100, but were found both within and outside of chondrules in CM2 Yamato 82042. It should be noted that aragonite is also known from carbonaceous chondrites (Barber, 1981), and in many instances the distinction between aragonite and calcite would not be obvious based on chemical analysis alone. Since aqueous processing was apparently necessary to form carbonates, one would expect carbonates to 
commonly be associated with materials that have experienced aqueous alteration. However, the observed correlation is erratic and sometimes this trend is reversed. For instance, ALH 83100 is less-extensively altered and yet has the highest carbonate abundances, in contrast to the extensively altered Kaidun CM1 lithology which shows limited occurrence of carbonate (calcite) (Hutcheon et al., 1999; Zolensky and Ivanov, 2003), possibly due to the removal of carbonate under retrograde low temperature conditions (Zolensky et al., 1997).

Carbonates show various styles of association with organic matter. Aqueous processes can precipitate carbonates, and these same processes are also capable of synthesizing organic molecules exhibiting the molecular asymmetry that characterizes life on Earth (Cronin and Pizzarello, 1997; Glavin et al., 2012). The carbon isotopic composition $\left(\delta^{13} \mathrm{C}\right)$ of unheated CM carbonates (+25 to $+75 \%$ ) (Alexander et al., 2015) and CM extraterrestrial amino acids $(+8$ to $+53 \%$ ) (Pizzarello et al., 2004) are more comparable to each other as opposed to solvent/acid IOM (-34 to $-17 \%$ ) (Alexander et al., 2007). Organo-carbonate associations in terrestrial aqueous settings allow the adsorption of organic matter onto carbonate mineral surfaces, which make carbonate an effective medium for the accumulation and concentration of organic matter, including carboxylic acids, amino acids, fatty acids, etc. (Suess, 1970, 1973; Carter and Mitterer, 1978; Thomas et al., 1993).

Carbonates commonly occur as single grains or grain assemblages in CM chondrites, and less frequently as veins, which are products of aqueous alteration on the CM parent body after accretion. Previous electron microprobe studies revealed that the carbonates in CM were predominantly Ca-Mg carbonates (1.4-2.8 vol\% of CM chondrites) (Johnson and Prinz, 1993; Zolensky et al., 1997; de Leuw et al., 2010) but could not distinguish between calcite and its high-pressure polymorph aragonite. Optical properties can be used to differentiate the 
two but it is not always applicable. Raman spectroscopy is sensitive to mineral structure, and offers a quick and reliable technique to distinguish between calcite (trigonal; space group $R \overline{3} c$ ) and aragonite (orthorhombic; space group - Pmcn), based on positions of bands in the low wavenumber $\left(100 \mathrm{~cm}^{-1}\right.$ to $\left.400 \mathrm{~cm}^{-1}\right)$ region (Fig. 2). Properly performed, Raman spectroscopy provides a non-destructive technique for characterizing meteorite mineralogy and organic chemistry. Many carbonaceous phases are Raman active, and Raman spectroscopy allows the differentiation of organic from inorganic materials, and the mapping of their spatial distribution. Our current knowledge of the distribution of organics in meteorites is especially limited (e.g., Clemett et al., 2012; Steele et al., 2012), and Raman spectroscopy offers an ideal method to observe the spatial relationships between organics and inorganic mineral phases at the microscopic scale. Raman spectroscopy is routinely used to identify carbonaceous materials and interpret their metamorphic history by revealing the structural organization (order) of the polyaromatic organic phases. Carbonaceous materials feature Raman bands in the first- and second-order regions (Nemanich and Solin, 1979; Beyssac et al., 2002b). The most typical peaks are the first-order defect (D) band at $~ 1350$ $\mathrm{cm}^{-1}$ and the graphite $(\mathrm{G})$ band at $\sim 1580 \mathrm{~cm}^{-1}$ (Tuinstra and Koenig, 1970a, b). The peak parameters of the D and G bands, such as the peak center locations (usually referred to as peak position), peak widths in terms of full width half-maximum (FWHM), and peak intensity ratios, were documented to systematically correlate with various properties of OM in meteorites, which can be used to estimate the structure and crystallinity of carbonaceous materials and the degree of thermal metamorphism (Busemann et al., 2007). Although the values of the peak parameters are highly dependent on the conditions of the instrument, experimental and peak fitting methods, which compromises the accurate determination of the metamorphic temperature, Raman spectroscopy offers better sensitivity, accuracy and reliability as a carbon thermometer compared to techniques such as X-ray Absorption Near- 
Edge Structure (XANES) spectroscopy (Quirico et al., 2011), and therefore can offer an estimate of the peak metamorphic temperature (PMT) experienced by the inorganic matter (IOM).

This paper presents a study of the structure of the organic matter (OM) in the matrix and carbonate phases in five CM chondrites: Jbilet Winselwan, Murchison, Nogoya, Santa Cruz, and Wisconsin Range (WIS) 91600. Based on results of Raman analysis, we determined the degree of maturation of the $\mathrm{OM}$ in these meteorites, the extent and relative timing of the aqueous events, and the formation conditions of the carbonates. We describe the organocarbonate relationships in these meteorite samples, which impacts the use of isotopic dating of carbonates to determine the ages of carbonate precipitation and the associated aqueous alteration events.

\section{EXPERIMENTAL PROCEDURES}

\subsection{Meteorite samples}

We studied five CM chondrites - Jbilet Winselwan (hereafter, Jbilet) (CM2.3 (Pernet-Fisher et al., 2014), a find from the Western Sahara, 2013. Jbilet is an unusual CM as it contains evidence of impact shock while also exhibiting hydration features (Zolensky et al., 2015). Here we compare our results to the hydrous lithology in light of the presence of carbonate likely associated with aqueous processing), Murchison (CM2.5 (Rubin et al., 2007), a fall from Australia, 1969), Nogoya (CM2.2 (Rubin et al., 2007), a fall from Argentina, 1879), Santa Cruz (CM2, a fall from Mexico, 1939), and WIS 91600 (CM2TII (Tonui et al., 2014), a find from Antarctica, 1991). The classification given by Rubin et al. (2007) indicates an aqueous alteration sequence that ranges from moderately-altered rocks (subtype 2.6) to highly-altered rocks (subtype 2.0, also classified as CM1 under the scheme described in van 
Schmus and Wood (1967). Nakamura (2005) further classifies the heated hydrous carbonaceous chondrites into Stages I-IV. Tonui et al., (2014) adopted this scheme to classify the heated WIS 91600 and thus this meteorite is referred to as type CM2TII in this study.

The Nogoya sample was obtained from Arizona State University, the WIS 91600 sample was provided by the Meteorite Working Group, the Santa Cruz sample was provided by the Smithsonian Institution National Museum of Natural History, and the remaining samples were provided by meteorite collectors. We prepared polished thin sections of the meteorite samples with all cutting and polishing done in isopropanol (rather than water) with alumina, and then identified carbonates in each sample with an optical microscope (Fig. 1).

Mechanical polishing artifacts have been previously reported to influence Raman spectra due to the disruption of the soft, opaque carbonaceous phases, which have a high extinction coefficient of visible-light in standard petrographic thin sections (Pasteris, 1989; Beyssac et al., 2003; Fries and Steele, 2011). Analyzing these opaque carbonaceous phases with Raman spectroscopy is not advisable because the visible-light from the laser beam only excites the uppermost layer $(<1 \mu \mathrm{m})$ of the thin section, which is the portion of sample that is disrupted by mechanical polishing, resulting in an unrepresentatively low OM structural order signal. However, as we compare the OM between the organic phases of the matrix and carbonates within a sample, and the majority of the studied OM is of low structural order, the potential damage due to mechanical polishing is of little concern in this study. We recommend using a VibroMet polisher for the final polishing step, which can prepare high quality polished surfaces by removing small-scale surface defects (it is commonly used for preparing samples for electron back-scattering diffraction analyses which are highly sensitive to surface defects). 


\subsection{Raman spectra of standard carbonates}

We obtained Raman spectra for standard carbonate minerals (aragonite $\left(\mathrm{CaCO}_{3}\right)$, calcite $\left(\mathrm{CaCO}_{3}\right)$, dolomite $\left(\mathrm{CaMg}\left(\mathrm{CO}_{3}\right)_{2}\right)$ and siderite $\left.\left(\mathrm{FeCO}_{3}\right)\right)$ which were used as reference spectra for identifying carbonates in the CMs. A common concern when studying carbonates with Raman spectroscopy is that the crystals can be damaged or modified by laser heating. The degree of laser beam damage to carbonates depends on their individual properties, such as thermodynamic stability (e.g., magnetite observed in the Martian meteorite ALH 84001 was suggested to have formed from siderite through thermal decomposition (Golden et al., 2001)) and optical absorbance (opaque materials are more susceptible to excitation beam damage). Although carbonates are generally colorless, some carbonates, such as siderite and malachite $\left(\mathrm{Cu}_{2}\left(\mathrm{CO}_{3}\right)(\mathrm{OH})_{2}\right)$, are colored or opaque, or commonly contain sub-microscopic opaque inclusions such as magnetite. For these reasons, carbonates are susceptible to laser beam damage, and the laser power should be properly adjusted when analyzing carbonates to minimize thermal alteration (Cooney et al., 1999). In light of this, we analyzed the carbonate standards by varying the excitation parameters such as exposure time and laser intensity (controlled by placing various filters in the beam path) to empirically determine the upper threshold of laser power density and exposure time that could be used for Raman analysis without damaging the sample. Although we did not observe any physical damage for calcite and dolomite, laser induced physical damage was observed for siderite (marked by an arrow in Fig. 2). Increasing the total laser power resulted in an intense fluorescence signal contributed by photo-oxidation effects. All Raman analyses were carried out with the optimized analytical parameters described in the next section. 


\subsection{Experimental apparatus}

The CM2 samples were analyzed using a Jobin-Yvon Horiba LabRam HR (800 mm) Raman microprobe at the Department of Geosciences, Virginia Tech. The excitation source was a $514.53 \mathrm{~nm}$ (green) laser provided by a Modu-Laser Stellar Pro-L 514 nm, 100 Mw solid-state laser (operated at $50 \mathrm{~mW}$ at the source). The slit width and the confocal pinhole aperture were set at $100 \mu \mathrm{m}$ and $200 \mu \mathrm{m}$, respectively, and a 600 grooves/mm grating was used to disperse the Raman signal. The laser beam was focused through a microscope equipped with a 40× objective, and the Raman backscattered light was collected from the same objective. The numerical aperture (N.A.) of the objective was 0.55 , and the Raman probe spatial resolution at the analyzed spot was $\sim 1.14 \mu \mathrm{m}$ at this magnification and for the laser used. At least 6 spectra were collected for each sample in the spectral range of $100 \mathrm{~cm}^{-1}$ to $4000 \mathrm{~cm}^{-1}$ with the use of a 600 grooves $/ \mathrm{mm}$ grating. This spectral range includes the first- and secondorder Raman bands of carbon. The exposure time for each spectrum was 20 s and three accumulations were obtained for each analytical spot to identify and discard spurious signals, such as those from cosmic rays, leading to a total acquisition time of up to 180 s with the use of an Extended Range option to collect data in various spectral windows. The laser power at the sample surface was $<2.25 \mathrm{~mW}$, using operating parameters that were fine-tuned to provide data of adequate signal to noise ratio. In the event that higher laser powers were required, the sample surface was reexamined to check for any damage. Peak position was calibrated daily against a silicon wafer prior to sample analyses.

Raman analysis of poorly-ordered polyaromatic OM is affected by the duration of laser irradiation and laser intensity, which must be carefully adjusted with reference to the size and optical characteristics of the samples in order to avoid irreversible thermal damage. Obvious thermal damage is evidenced by a visibly burnt spot on the sample surface. However, laser 
irradiation does not only cause physical damage, but also photo-oxidation effects (Quirico et al., 2005b). Such alteration effects are difficult to recognize by visual observation, and are usually misidentified as 'intrinsic' oxidized materials. To minimize laser damage, we followed a carefully controlled analytical protocol (exposure time, laser filter, etc.), and monitored the physical damage through inspection of the samples for signs of visible damage before and after each laser scan. Spectra from samples that showed laser damage after the analysis were not included in our peak parameter calculations.

\subsection{Curve-fitting and baseline correction}

Spectral parameters are obtained after appropriate baseline correction and peak fitting procedures. However, a single curve-fitting model does not always provide the best fitting result for all curve shapes. While some studies select a single curve-fitting model to allow comparison with previous studies, in other studies a particular curve-fitting model was used because it provided the best fit to their data, which makes comparison of data between different studies difficult. The different peak-fitting models that have been used to interpret Raman spectra of carbonaceous materials include 2-band models: Lorentzian and BreitWigner-Fano (BWF) profiles (Bonal et al., 2006; Bonal et al., 2007; Quirico et al., 2009b), two Lorentzian profiles (Matrajt et al., 2004; Quirico et al., 2005a; Caro et al., 2006; Busemann et al., 2007), two Gaussian profiles (Fries et al., 2011), symmetric and asymmetric Voigt profiles (Thomas-Keprta et al., 2014), 3-band models: three Lorentzian profiles (Nemanich and Solin, 1979), 4-band models: Voigt (Beyssac et al., 2002a; Beyssac et al., 2002b; Rahl et al., 2005; Maslova et al., 2012), Lorentzian (Ferrari and Robertson, 2004), and pseudo-Voigt profiles (Kouketsu et al., 2014), and 5-band models: pseudo-Voigt and Lorentzian profiles (Kouketsu et al., 2014) and five Lorentizian profiles (Bernard et al., 2010; Lahfid et al., 2010). 
The peak position $(\omega)$ and full width half-maximum (FWHM, $\Gamma$ ) of each Raman band were determined by simultaneous peak fitting to Lorentzian profiles and linear baseline correction. We used a Lorentzian model for the following reasons: (1) the OM in the CMs are largely composed of disordered graphitic carbon and the use of Voigt profiles increases the degrees of freedom which reduces the reproducibility for a given spectrum, (2) to facilitate comparison with previous studies, (3) higher coefficient of determination $\left(\mathrm{r}^{2}\right)$ values, indicating better fit (see Fig. 3), and (4) further instrumental broadening effects can be solved by fixing an additional Gaussian width in the Voigt profile which is well presented by a pure Lorentzian profile (Meier, 2005). Weak fluorescence background was subtracted using a linear (Matrajt et al., 2004; Quirico et al., 2005a; Bonal et al., 2006; Bonal et al., 2007; Busemann et al., 2007; Quirico et al., 2009b; Maslova et al., 2012; Kouketsu et al., 2014), spline (Caro et al., 2006; Fries et al., 2011), and Lorentzian baseline (Nemanich and Solin, 1979).

An example of peak fitting is presented in Fig. 4. The fluorescence background in the Raman spectrum is weak and therefore baseline removal was accomplished by subtracting a linear baseline defined by the two end points of the selected spectral range $\left(1000 \mathrm{~cm}^{-1}\right.$ to $1800 \mathrm{~cm}^{-1}$, which covers the overlapping carbon bands of interest). We eliminated spectra that showed a significant fluorescence contribution, producing a non-linear baseline that could significantly affect the peak fitting results. For carbonate identification, after visual comparison of the raw Raman spectra of the samples to the carbonate standards (Fig. 2b), the exact peak positions were determined by fitting four Lorentzian profiles to the spectral regions of around 160, 285, 715 , and $1090 \mathrm{~cm}^{-1}$, which correspond to the typical vibration modes of calcite/dolomite (Table 1). 


\section{RESULTS}

\subsection{Raman spectra of carbonates and their implications}

Representative Raman spectra of the carbonates in the CM2 meteorite samples are shown in Fig. 5. Carbonates were first identified by optical examination and confirmed by the distinctive intense Raman band in the $\sim 1100 \mathrm{~cm}^{-1}$ region which represents the symmetric stretching vibration mode $\left(v_{1}\right)$ of the $\left(\mathrm{CO}_{3}\right)^{2-}$ anion (Cloots, 1991). The peak position of this Raman band spans the range of $1088-1100 \mathrm{~cm}^{-1}$. This range corresponds to the metaloxygen bonding in carbonates (Sun et al., 2014), in which cation contents can affect the width and position of the $v_{1}$ Raman bands. We compared the $\sim 1100 \mathrm{~cm}^{-1}$ band positions of the CM carbonates to the dolomite and calcite standards (Fig. 5, Table 1). The locations of the dolomite Raman bands are typically $\sim 10 \mathrm{~cm}^{-1}$ higher than those for calcite. For example, the $v_{1}$ vibration mode peak is at $1097 \mathrm{~cm}^{-1}$ for dolomite but shifts to $1087 \mathrm{~cm}^{-1}$ for calcite. Table 1 lists the peak positions and the corresponding assignments of calcite and dolomite standards to illustrate the comparison between the two. We determined that most selected carbonates identified in the CM chondrites in this study are calcite, except for a single dolomite grain in Nogoya (Grain 5). This does not preclude the presence of other carbonate phases in the CMs. The $v_{1}$ positions of the $\mathrm{CM}$ calcites are $2-3 \mathrm{~cm}^{-1}$ higher than in pure calcites $\left(\mathrm{CaCO}_{3}\right)($ Table 1), which suggests that the CM calcites contain other cations substituting for $\mathrm{Ca}$ in the calcite structure. The other cations in the Ca-carbonates are mainly $\mathrm{Fe}$, and occasionally $\mathrm{Mn}$ and $\mathrm{Mg}$, in CMs (Johnson and Prinz, 1993; Zolensky et al., 1997), and Sr in CIs (Fredriksson and Kerridge, 1988). A close-up view of other minor vibration modes is also provided in Fig. 5c. These modes can be attributed to the calcite/dolomite $\left(\mathrm{CO}_{3}\right)^{2-}$ group asymmetric stretching mode $\left(v_{3}\right)\left(1200-1700 \mathrm{~cm}^{-1}\right.$ region), symmetric deformation mode $\left(v_{4}\right)\left(715-726 \mathrm{~cm}^{-1}\right)$, and external vibration mode due to the relative translations between the cation and anionic groups 
$\left(\sim 155-175 \mathrm{~cm}^{-1}\right.$ and $\sim 285-300 \mathrm{~cm}^{-1}$ ) (see Gunasekaran et al., 2006 and references therein for peak assignments).

The width of the $\sim 1100 \mathrm{~cm}^{-1}$ band of carbonate in meteorites has been suggested to be significantly broader than that in terrestrial end-members (the peak widths of the terrestrial calcite and dolomite standards in this study are $\sim 7 \mathrm{~cm}^{-1}$ ) (Cooney et al., 1999). The peak width of calcite in WIS 91600 is $13 \mathrm{~cm}^{-1}$, however, the peak widths are much narrower $(9 \mathrm{~cm}$

${ }^{1}$ for dolomite; $<5 \mathrm{~cm}^{-1}$ for calcite) for all other CM carbonates in this study. Raman band broadening can be attributed to various factors, including the crystallinity of the sample, structural defects and fluorescence effects, and external factors that are influenced by experimental conditions such as the groove density of the grating used. While keeping the experimental conditions consistent, the Raman band broadening observed for WIS 91600 can be explained by the structural disorder in its carbonate crystal lattice, whereby $\mathrm{CO}_{3}{ }^{2-}$ ions are “tilted" out of the crystallographic basal plane (Bischoff et al., 1985; Cooney et al., 1999). Cooney et al. (1999) proposed several hypotheses to explain the band broadening effect observed for carbonate in ALH 84001. They attributed the Raman band broadening in ALH 84001 calcite and the presence of amorphous plagioclase to post-shock annealing effects and argued for complex thermal and shock histories for this meteorite. While these hypotheses should be tested with further experimental studies, a possible link can be drawn to support an alteration history with short duration heating derived from impact events, as was previously proposed for WIS 91600 by Yabuta et al. (2010).

\subsection{Organo-carbonate associations}

The excellent Raman spatial resolution $(\sim 1.14 \mu \mathrm{m})$ and large carbonate grain sizes (28 to 318 $\mu \mathrm{m})$ allowed accurate analyses of the carbonate grains without interference from surrounding 
phases. Raman laser irradiation typically interacts with the sample surface, and the irradiation volume would be larger when studying transparent materials. In this study, the analyzed carbonate grains are large enough so that the Raman features do not contain signals from materials beneath the grain. Fig. 6 provides a good example of this effect - the carbonate grain of Nogoya is the smallest, and yet while D and G bands are clearly present in the matrix, they are absent from the Raman spectra of the carbonate.

Typical first-order D bands at $\sim 1350-1380 \mathrm{~cm}^{-1}$ and the $\mathrm{G}$ band at $\sim 1580-1590 \mathrm{~cm}^{-1}$ were detected in $\sim 25 \%$ of the analyzed carbonate grains in the meteorite samples (Fig. 6), indicating the presence of disordered organics in the carbonates. This suggests that carbonates not only provide sources of carbon from their carbonate frameworks, but also trap and preserve organic carbon present in the mineralizing fluids. However, while the D and G bands were observable in the matrix of Murchison, its carbonate crystals are devoid of organic matter at levels detectable by Raman analysis. In fact, carbonates generally do not contain Raman-active organic matter, while the matrix in the CM meteorite samples in this study always shows D and G Raman bands. The different occurrences of carbonate have been described previously (e.g, Grady et al., 1988; Tyra et al., 2007; Tyra et al., 2012; Lee et al., 2014). Further details are presented in the Discussion section.

The Raman parameters of the CM2 samples are listed in Table 2, and the data are plotted in Fig. 7 to illustrate the peak parameter correlations. The observed variations in the peak parameters reflect organic heterogeneities in the $\mathrm{CM}$ chondrites, which indicate the presence of different chemical components, relative OM maturity, and/or different alteration history (e.g. temperature, duration of the heating event). We have minimized the uncertainties in chemical variation and organic compositions by focusing our study on CM2 chondrites, as it 
was reported by Quirico et al. (2009b) that Raman spectra of poorly-ordered materials are sensitive to the nature of the organic precursors. While the Raman peak parameters of the CM samples conform to the IOM of primitive chondrites, they also exhibit well-defined trends and are distinguishable between carbonate phases and matrix (Fig. 7). The variations of the carbonate and matrix peak shapes are even recognizable from initial visual examination of peaks in the raw Raman data, such as for Jbilet Grain 2 (Fig. 6). After peak decomposition, it was found that the $\mathrm{OM}$ in carbonates generally has comparatively narrower band widths $\left(\Gamma_{\mathrm{D}}\right.$, $\left.\Gamma_{\mathrm{G}}\right)$, lower $\mathrm{I}_{\mathrm{D}} / \mathrm{I}_{\mathrm{G}}$ ratios, but higher wavenumber $\mathrm{G}$ band positions $\left(\omega_{\mathrm{G}}\right)$. The correlation between the $\mathrm{D}$ band parameters is less prominent, however the Raman peak parameters of the carbonate carbon is clearly distinct from matrix organics. The D band position and band width of carbonate in Jbilet, for example, are distinctively lower than the matrix. Less primitive (more thermally-altered) meteorites generally show lower (narrower) $\Gamma_{\mathrm{D}}$ and $\Gamma_{\mathrm{G}}$ values, and $\omega_{\mathrm{D}}$ and $\omega_{\mathrm{G}}$ that are shifted to higher wavenumbers (Busemann et al., 2007). Although some studies show benefits of using $\mathrm{G}$ band parameters over the D bands due to the controversial origin of the D bands (e.g., Fries et al., 2009), Quirico et al. (2011) pointed out that there is a lack of correlation between $\Gamma_{\mathrm{G}}$ and $\mathrm{OM}$ maturity (a detailed account of the correlations between the peak parameters and OM maturity will be given in the Discussion section 4.2). Our Raman data show a positive correlation between the $\Gamma_{\mathrm{D}}$ and $\Gamma_{\mathrm{G}}$ values, as well as between $\Gamma_{D}$ and the Raman intensity ratio $I_{D} / I_{G}$ (Fig. 7a,d). A negative correlation was observed for $\mathrm{G}$ parameters (Fig. 7b), which agrees with the data reported for disordered OM in chondrites (Bonal et al., 2006; Busemann et al., 2007).

It is worth mentioning here that we have applied appropriate curve-fitting models when comparing our results to a carbon thermometer given in a specific study. To make accurate cross-laboratory comparisons with our results, when using the cosmothermometer provided 
by Busemann et al. (2007), we used a two Lorentzian profiles model to obtain the Raman peak parameters. Nevertheless, variation in programming algorithms resulted in notable disparities in peak parameters despite the use of a similar peak-fitting model. For example, with the use of a two Lorentzian profiles model, the $\Gamma_{\mathrm{D}}$ values were $\sim 300 \mathrm{~cm}^{-1}$ (Quirico et al., 2005a), 290-330 $\mathrm{cm}^{-1}$ (Busemann et al., 2007), and $\sim 380 \mathrm{~cm}^{-1}$ (this study) for Murchison. This variation probably also represents sample heterogeneity, different instrument conditions, and/or different sample preparation methods (e.g., Busemann et al. (2007) extracted the IOM grains from raw samples by $\mathrm{HF} / \mathrm{HCl}$ acid treatments, while Quirico et al. (2005a) analyzed the meteorite matrix directly).

\section{DISCUSSION}

\subsection{Carbonates reflect the degree of parent-body aqueous alteration}

CM2 chondrites contain abundant Ca carbonates that commonly occur as small grains (10-60 $\mu \mathrm{m}$ ), and occasionally as veins in the matrix (e.g., Bunch and Chang, 1980; Johnson and Prinz, 1993; Rubin et al., 2007; Lee et al., 2014). We have identified large carbonate grains in the CM2 meteorite samples (up to $318 \mu \mathrm{m}$ in Jbilet) (Fig. 6, Supplementary Figures S1 and S2). Carbonates are generally thought to occur as secondary minerals that precipitate from aqueous solutions circulating within the parent bodies or were formed by replacement of other preexisting minerals, such as olivine, during aqueous processes (e.g., McSween, 1979; Bunch and Chang, 1980; Fredriksson and Kerridge, 1988; Grady et al., 1988). In light of this correlation, the overall and relative abundances of different carbonates should reflect the degree of aqueous alteration on the parent body. Changes in carbonate mineralogy reflected by the increase in the abundances of complex (Mg-Fe-Mn-Ni-bearing) carbonates at the expense of Ca carbonate also indicate the extent of alteration (Zolensky et al., 1997). 
The presence of $\mathrm{Ca}$-carbonate indicates aqueous alteration, but progressive aqueous alteration results in more complex carbonate compositions (cation substitution), which can ultimately lead to their disappearance (e.g., Rubin et al., 2005). To illustrate, calcite is the only or dominant carbonate phase in the less-altered CM chondrites such as CM2.5/CM2.7 Murchison (Brearley et al., 1999), rare dolomite is present in the more extensively-altered CM chondrites such as CM2.2 Nogoya, CM2.1 QUE 93005, and CM2.1 ALH 83100, which also have the highest carbonate abundances (e.g., Grady et al., 1988; de Leuw et al., 2010). However, no/limited carbonates were found in the most extensively altered Kaidun CM1 lithology or EET 83334 (Zolensky et al., 1997; Hutcheon et al., 1999). Complex carbonates were also found to form partial rims around Ca carbonates suggesting that the complex carbonates formed after the Ca carbonates (Rubin et al., 2007). However, there are exceptions to this general trend, such as CM1 ALH 88045, which is an extensively altered chondrite that contains only calcite or aragonite but no dolomite (Zolensky et al., 1997).

Our observations indicate that the five selected CM2 have all experienced typical levels of aqueous processing, as evidenced by the presence of considerable amounts of Ca carbonates. Among the five CM2s in this study, Murchison, which is classified as a CM2.5, shows less intense aqueous alteration compared to CM2.3 Jbilet and CM2.2 Nogoya (Rubin et al., 2007). The $v_{1}$ peak positions of the calcites in the CM2 samples are $2-3 \mathrm{~cm}^{-1}$ higher than in pure calcites, which indicates that they contain significant levels of cations other than $\mathrm{Ca}$ (Table 1), implying that even the less-altered Murchison has been exposed to significant aqueous alteration (which was of course already known from the high content of phyllosilicates). The presence of dolomite in Nogoya suggests that it is derived from a more extensively-altered region of the parent body, compared to the other CMs. This finding supports the result presented in Johnson and Prinz (1993), who reported the occurrence of dolomite in Nogoya. 
Jbilet is known to exhibit a complex alteration history evidenced by the presence of (1) moderate to pervasive aqueous alteration material based on its Poorly Characterized Phases (PCP - a now invalid name for tochilinite) index (Pernet-Fisher et al., 2014), (2) heated components as indicated by its nitrogen and noble gas data (Grady et al., 2014), and (3) melted troilite which suggests a flash heating event (Zolensky et al., 2015). While carbonate was found to be absent in some Jbilet samples, suggesting a portion of Jbilet has escaped aqueous alteration (Grady et al., 2014), the Jbilet sample of this study is more comparable to the sample reported by Pernet-Fisher et al (2014) which shows a substantial degree of aqueous alteration. This stresses that the complicated alteration history also occurs on the scale of an individual meteorite. Nevertheless, considering the small number of thin sections and carbonates studied and their typically brecciated, heterogeneous nature, it is premature to conclude that more complex carbonates are absent from these CM2 samples.

The organic compositions of the analyzed carbonates in the CM samples show notable variations (Table 2). All the analyzed carbonate grains (calcite) observed in Murchison samples lacked typical Raman OM features. Calcite grains in Nogoya were also barren of organics, but the dolomite grain (Grain 5) contains OM showing a degree of maturation that is distinctive from the organics observed in Nogoya matrix. Jbilet and Santa Cruz are hosts to a mixture of carbonate grains, with and without organics. Calcite in WIS 91600 contains organics, however, since only one carbonate crystal was available for analysis due to the small sample size, it is yet to determine whether organic-barren carbonate is present in this sample. Our Raman observations suggest that carbonates in the CM meteorites were produced under diverse chemical conditions, perhaps with an evolving fluid composition, or different sources of fluid. This is supported by the view that different carbonates might not have formed under equilibrium conditions from the same fluid (Riciputi et al., 1994). 
Differences in the nature of carbonate phases in different CMs were also noted in previous studies based on isotopic and petrologic observations (e.g., Grady et al., 1988; Tyra et al., 2007; Tyra et al., 2012; Lee et al., 2014). Tyra et al. (2007; 2012) categorized the CM Cacarbonates into three types: type 1 - small inclusion-free grains $\left(\delta^{18} \mathrm{O}\right.$ value $\approx 34 \%$ ); type $2-$ large aggregates containing inclusions $\left(\delta^{18} \mathrm{O}\right.$ value $\approx 19 \%$ ); type 3 - vein-infill grains (formed by terrestrial weathering processes, $\delta^{18} \mathrm{O}$ value $\approx 3 \%$ ). Type 1 carbonate is found in the matrix of most $\mathrm{CM}$ chondrites, but type 2 carbonate is only present in the more aqueously-altered CM chondrites like Nogoya (Browning et al., 1996; Rubin et al., 2007). Type 2 carbonate is generally absent in CMs that were less altered, such as Murchison. The petrology and oxygen isotope compositions of types 1 and 2 carbonate suggest that type 1 carbonate was the earlier of the two carbonate generations (Tyra et al., 2012; Lee et al., 2013). In this context, type 2 carbonate is comparable to the carbonates that show typical Raman OM features, which were identified in all CM chondrites investigated in this study except for Murchison, while type 1 carbonate is comparable to the carbonate grains which lack typical Raman OM features. Yet, the carbonate crystal forms of type 2 (OM-bearing) carbonate do not strictly conform to the general descriptions given in previous studies. Although "type 2" carbonate was reported to occur as pseudomorphs replacing chondrule silicates in some CM2 chondrites such as Nogoya (Benedix et al., 2003), such petrographic evidence is not obvious in this study. Some OM-bearing carbonates also occur as large single grains instead of rounded aggregates. For example, the consistency in the Raman peak intensity ratio between the $\sim 285$ and $\sim 1090 \mathrm{~cm}^{-1}$ peaks throughout the calcite grain in Jbilet suggests that this crystal grain belongs to a single grain instead of an agglomerate of tiny calcite crystals (Supplementary Figure S2). Further studies of the isotopic composition of the carbonates in these meteorite samples may elucidate their correlation to the types 1 and 2 carbonate 
previously described. The carbon source(s) of the carbonate and OM in CM chondrites will be further discussed in Section 4.3.

\subsection{Maturation grade of organic matter in the CM matrix}

The meteorite petrologic type classification scheme reflects either increasing aqueous alteration or increasing thermal metamorphism (e.g., Van Schmus and Wood, 1967;

Weisberg et al., 2006). Sub-classification of CM samples shows varying degrees of aqueous alteration (e.g., McSween, 1979; Browning et al., 1996; Rubin et al., 2007; Alexander et al., 2013) and moderate to severe thermal metamorphism (e.g., Nakamura, 2005; Huss et al., 2006; Alexander et al., 2007; Tonui et al., 2014). Petrologic assignment for mildly-heated meteorites that were processed by both thermal and aqueous alterations is challenging but there are studies which address this range of samples (e.g., Quirico et al., 2014). In this study, we will compare the degrees of heating of the CM2 meteorite samples by referring to the maturation grade of their matrix OM.

Although the Raman parameters are less diagnostic for determining the structure of individual aromatic units of polyaromatic OM (Tuinstra and Koenig, 1970a, b; Wopenka and Pasteris, 1993; Quirico et al., 2003; Quirico et al., 2005a), they are sensitive to the structure of the aromatic skeleton and the nature the organic precursor (Quirico et al., 2009b), and thus are useful for estimating the degree of structural order of the $\mathrm{OM}$ in terms of metamorphic grade (e.g., Beyssac et al., 2002a; Quirico et al., 2003; Bonal et al., 2006; Bonal et al., 2007; Busemann et al., 2007; Aoya et al., 2010; Kouketsu et al., 2014). A perfect crystalline graphite possesses $\mathrm{D}_{6 \mathrm{~h}}{ }^{4}$ space group symmetry and exhibits vibration modes $2 \mathrm{E}_{2 \mathrm{~g}}+2 \mathrm{~B}_{2 \mathrm{~g}}+$ $\mathrm{E}_{1 \mathrm{u}}+\mathrm{A}_{2 \mathrm{u}}$. Only the $2 \mathrm{E}_{2 \mathrm{~g}}$ double degenerate in-plane vibration modes are Raman active, and the $\mathrm{E}_{2 \mathrm{~g} 2}$ corresponds to the $\mathrm{G}$ band, which is due to the stretching mode in both rings and 
chains, and is present in all organic matter regardless of the degree of structural order (Tuinstra and Koenig, 1970b; Castiglioni et al., 2004; Ferrari and Robertson, 2004). The peak position of the $\mathrm{G}$ band is a function of the energy of vibrational modes in the crystalline domains, and thus represents the mean size of those domains. Therefore, a sharp G band identifies well-crystalline graphitic materials. The Raman spectra of finite-sized microcrystallites (in-plane crystallite diameter, $L_{a}<1000 \AA$ ) and materials with disrupted crystal symmetry (i.e. increasing the degree of disorder by introducing edges, defects) contain D bands (Wang et al., 1990), which are not present in perfectly-stacked graphite. The D bands correspond to the breathing modes in rings, therefore they are absent without the presence of aromatic structure (Ferrari and Robertson, 2004). So far, four D bands have been observed in the first order region, including the D1 $\left(\sim 1350 \mathrm{~cm}^{-1}\right)$, D2 (or $\left.\mathrm{D}^{\prime}\right)\left(\sim 1620 \mathrm{~cm}^{-1}\right)$, D3 $\left(\sim 1510 \mathrm{~cm}^{-1}\right)$ and D4 $\left(\sim 1200 \mathrm{~cm}^{-1}\right)$ bands (Beyssac et al., 2002b; Bernard et al., 2010; Kouketsu et al., 2014). The D1 band represents in-plane defects arising from the presence of heteroatoms such as hydrogen, nitrogen and oxygen (Beny-Bassez and Rouzaud, 1985), but the origin and corresponding vibration modes of the other D-bands are still unresolved. The full width at half maximum (FWHM, $\Gamma$ ) is a function of the distribution of the sizes of crystalline domains, and crystalline domains are larger for high temperature materials (Bower et al., 2013), the D and G bands become narrower at high temperatures, while the intensities of the $\mathrm{D}$ bands are reduced as compared to the $\mathrm{G}$ band. The combination of these peak parameters describes the overall size distribution of the crystalline domains and the metamorphic history of the host.

The wide peak widths of $\Gamma_{\mathrm{D}}$ and $\Gamma_{\mathrm{G}}$ of the matrix $\mathrm{OM}$ in the five $\mathrm{CM}$ chondrites are indicative of highly disordered carbonaceous materials composed of molecules with conjugated bonds that occur as polyaromatic or amorphous OM. The structure of the CM 
organics could have been further altered through amorphization processes such as irradiation induced by cosmic rays and UV photons during their residence in the interstellar medium (Ferrari and Robertson, 2000; Caro et al., 2006). Amorphization can break $s p^{2}$ bonds and eventually lead to the formation of tetrahedral amorphous carbon. The more disordered nature of the $\mathrm{CM}$ matrix organics can also correlate to their younger accretion ages (3 Myr after the formation of the calcium-aluminium-rich inclusions (CAIs), the oldest Solar System solids, in CV chondrites), and thus a longer exposure to irradiation and $\mathrm{OM}$ amorphization, compared to other carbonaceous chondrites (Doyle et al., 2015).

A negative correlation between $\Gamma_{\mathrm{D}}$ and $\mathrm{I}_{\mathrm{D}} / \mathrm{I}_{\mathrm{G}}$ was observed for extraterrestrial carbon (e.g., Bonal et al., 2006), which was suggested to indicate increasing metamorphism due to the transition from amorphous carbon to nanocrystalline graphite, leading to a narrower $\Gamma_{\mathrm{D}}$ and larger $I_{D} / I_{G}$ (Ferrari and Robertson, 2000). As opposed to the reported negative correlation between $\Gamma_{\mathrm{D}}$ and $\mathrm{I}_{\mathrm{D}} / \mathrm{I}_{\mathrm{G}}$, these features were found to be positively correlated in this study (Fig. 7d). A similar positive correlation between $\Gamma_{D}$ and $I_{D} / I_{G}$ has also been observed for the deuterium (D)-enriched organic globules and matrix organic materials in the CR2 Northwest Africa (NWA) 801 (Hashiguchi and Yurimoto, 2016). Although a positive correlation between $\Gamma_{\mathrm{D}}$ and $\mathrm{I}_{\mathrm{D}} / \mathrm{I}_{\mathrm{G}}$ was suggested to indicate the onset of large-scale graphitization in the most metamorphosed samples such as CO3.7 Isna (Busemann et al., 2007), this does not apply to the CM2s in this study owing to the amorphous nature of the organics present in these samples. Instead, since the D bands represent in-plane defects, the narrower D bands indicate less structural defects for the carbonate organics compared to the matrix OM, or the presence of amorphous carbon with a different $s p^{2}$ clustering mechanism or $\mathrm{H}$ content (Ferrari and Robertson, 2000). 
Various carbon thermometers have been established in previous studies to estimate the PMT of IOM with reference to the carbon Raman parameters, based on empirical measurements of terrestrial (i.e. geothermometers) (Beyssac et al., 2002a; Quirico et al., 2003; Rahl et al., 2005; Bonal et al., 2007; Aoya et al., 2010; Kouketsu et al., 2014) and meteoritic carbon (i.e. cosmothermometers) (Busemann et al., 2007; Homma et al., 2015). The selection rationale of appropriate carbon thermometer is based on the nature of the organic precursor and the maturation grade of the IOM. For poorly-organized IOM, it is inappropriate to use the R2 ratio $\left[\mathrm{D} 1 /(\mathrm{G}+\mathrm{D} 1+\mathrm{D} 2){ }_{\text {Area Ratio }}\right]$ to determine the maturation grade as the extension of the coherent domains constituted by the aromatic rings is too small, therefore we cannot use the geothermometers provided by Beyssac et al. (2002a) and Rahl et al. (2005) in this study as both of the equations take into account the $\mathrm{R} 2$ ratio. The geothermometer given by Rahl et al. (2005) requires a properly fitted $\mathrm{G}$ band, which can result in large uncertainties when studying poorly-organized $\mathrm{OM}$ as it is impossible to separate the $\mathrm{G}$ and $\mathrm{D} 2$ components of the broad and featureless $\mathrm{G}_{\mathrm{L}}$ band at $\sim 1600 \mathrm{~cm}^{-1}$. Therefore, in this study, it would only be appropriate to estimate the PMT by referring to the cosmothermometers determined for meteoritic IOM given by Busemann et al. (2007) (PMT range: $200-600^{\circ} \mathrm{C}$ ) and Homma et al. (2015) (PMT range: $20-540^{\circ} \mathrm{C}$ ), which utilize only the band widths, $\Gamma_{\mathrm{D}}$. Estimated PMTs (carbonates: $217-257^{\circ} \mathrm{C}$; matrix: $292-363^{\circ} \mathrm{C}$ ) were calculated using the carbon cosmothermometer given by Busemann et al. (2007) (Equation 1, Table 2). The spectra of Jbilet Grain 2 show well defined shapes with prominent D1-D4 bands (Fig. 4), permitting a more accurate five-Lorentzian profiles peak-fitting procedure. We applied the cosmothermometer derived by Homma et al. (2015) (Equation 2) to estimate lower PMT range, and obtained a PMT of $\sim 140^{\circ} \mathrm{C}$ for the Jbilet calcite. The estimated PMTs calculated using the cosmothermometers given by either Busemann et al. (2007) or Homma et al. (2015) are much higher than the suggested alteration temperatures of $\mathrm{CM}$ chondrites $\left[0-130^{\circ} \mathrm{C}(\mathrm{e} . \mathrm{g}\right.$., 
Guo and Eiler, 2007; Alexander et al., 2014)], which possibly indicates that these aqueouslyaltered chondrites were subjected to a subsequent heating event at a temperature much higher than the alteration temperature. Although the Raman parameters are sensitive to the degree of structural order of the OM in terms of metamorphic grade, the calculated relative PMTs between the carbonate and the matrix do not agree with the observed Raman parameter correlations described in Fig. 7, as the OM in carbonates reflects a higher degree of structural order but the calculated PMT is lower than that of the matrix. Therefore, in the following text, the PMT estimates are interpreted with reference to the matrix OM. The variation between the OM maturity between the carbonate and matrix organics will be explored in Section 4.3.

$$
\begin{array}{lr}
\operatorname{PMT}\left({ }^{\circ} \mathrm{C}\right)=931-5.10 \times \Gamma_{\mathrm{D}}+0.0091 \times \Gamma_{\mathrm{D}}{ }^{2} & \text { Equation 1 } \\
\operatorname{PMT}\left({ }^{\circ} \mathrm{C}\right)=-6.9 \times \Gamma_{\mathrm{D} 1}+1054.4 & \text { Equation 2 }
\end{array}
$$

Our Raman data indicate that the degrees of heating experienced by the CM2 samples (matrix) follow the sequence: WIS $91600>$ Santa Cruz $\geq$ Murchison $\geq$ Jbilet $>$ Nogoya, and are comparable to the associated petrologic type given in the literature (Rubin et al., 2007; Pernet-Fisher et al., 2014). WIS 91600 is the most thermally-altered among the five CM2 samples. It was referred to as a partially aqueously altered and thermally metamorphosed $\left(<500^{\circ} \mathrm{C}\right) \mathrm{CM}$-like chondrite based on the well-preserved nature of chondrules and coarsegrained matrix silicates and the presence of Fe-rich phyllosilicates that appear to be transitional between serpentine and an anhydrous phase (Tonui et al., 2002; Yabuta et al., 2010). Tonui et al. (2014) classified WIS 91600 as a CM2TII thermally metamorphosed chondrite that has experienced up to Stage II heating (roughly $250-500^{\circ} \mathrm{C}$ ) based on petrographic, chemical and spectroscopic evidence. Short-duration heating has been given as 
a possible mechanism for the observed spectral feature of WIS 91600 (Quirico et al., 2009a; Yabuta et al., 2010), and the presence of phyllosilicates and carbonate also suggests that this meteorite was heated mildly (Nakato et al., 2009).

When compared to previous studies, the calculated PMTs are higher than the estimated PMTs from the Raman analysis given by Busemann et al. (2007) and Quirico et al. (2014) (Supplementary Table S1), possibly due to the differences in the sample preparation procedure [chemically extracted IOM in by Busemann et al. (2007) and Quirico et al. (2014)] and peak-fitting method [Lorentzian Breit-Wigner-Fano (LBWF) fit in Quirico et al. (2014)]. The variations in the $\mathrm{D}$ parameters in the matrix represents a polishing effect that leads to a wider $\Gamma_{\mathrm{D}}$. We note here that some samples of Jbilet also display effects of short-term shock heating (Grady et al., 2014; Zolensky et al., 2015), which were not exhibited by the sample we examined here, probably due to the heterogeneous nature of this meteorite.

Although the $\Gamma_{\mathrm{D}}$ appears to correlate well with the PMT and the cosmothermometers span a wide range of maturity of chondritic OM, estimation of PMT with the use of a general cosmothermometer is still not appropriate for the most primitive OM, which was pointed out by Busemann et al. (2007) as a downfall of this method. Most of the temperatures used to establish the cosmothermometer are limited to published metamorphic temperatures obtained from Huss et al. (2006), who focused on heated chondrites, rather than meteorites like CI and $\mathrm{CM}$ chondrites which have experienced pervasive aqueous alteration. The temperatures used to establish the cosmothermometers are only used as a general reference to the upper temperature limits experienced by the meteorites. Therefore, we are still lacking fundamental information needed for a reliable carbon thermometer, and thus further development is 
necessary in order to fully describe the nature of the chondritic OM in the most aqueouslyaltered end members.

The second-order region (2200 to $3400 \mathrm{~cm}^{-1}$ ) is useful for studying highly-graphitic materials. The Raman spectra of the meteorite samples show a significant fluorescence background in this region that is typical of carbon structures with conjugated bonds (Quirico et al., 2005a), which again suggests the presence of aromatic compounds. Similar observations have been made for other carbonaceous chondrites (Matrajt et al., 2004). Since the second-order region is masked by the fluorescence background, we cannot characterize this region of the spectra any further.

\subsection{Raman features of CM carbonates indicate different carbonate formation conditions}

The matrix OM of the CM meteorite samples in this study has a lower maturation grade than the carbonate organics (Fig. 7). Assuming that the OM maturity is strictly correlated to the degree of thermal metamorphism, this indicates that the carbonates were formed prior to the heating event experienced by the CM parent body matrix, and thus have experienced a higher degree of thermal metamorphism that was not recorded by the matrix OM. Many carbonaceous chondrites have experienced low-temperature hydration followed by hightemperature heating which could have altered the carbon structure of the carbonate organics (Nakamura, 2005), however this does not explain the variation in the OM maturity of the carbonate and matrix organics, as the matrix OM would reflect the same (or at least comparable) structural order as the carbonate organics. Although CM chondrites often contain xenolithic clasts that were brecciated and transported to a neighboring CM asteroid, which is similar to the scenario described for Kaidun (Zolensky and Ivanov, 2003), this case 
does not apply as only the carbonate grains, instead of the entire lithology that hosts the carbonates, contain OM with a higher structural order. Therefore, the differences observed for the Raman features between the carbonate and the matrix organics should indicate a variation in organic components. This also agrees with studies that suggested WIS 91600, for instance, contains two distinct domains of OM with different molecular structures and different average degrees of aromatic condensation, one of which experienced heating during an impact event (Yabuta et al., 2010). The spectral parameters of the organics in the matrix and in the carbonates are distributed along single maturity trends in the various graphs depicting Raman parameters (Fig. 7). The parameters of the matrix OM are more consistently distributed compared to that of the organics contained in the carbonate. Since different types of organic precursors should mature in a distinctive manner and thus should lead to discontinuities in the graphitization process (Wopenka and Pasteris, 1993), the maturity trend observed for the organics in matrix and carbonate suggests that they are likely derived from a similar source of precursors and/or exhibit a generic relationship. The clustering in the spectral parameters of matrix OM contrasts to the wide range observed for that of the carbonate $\mathrm{OM}$, suggesting that the matrix $\mathrm{OM}$ is more primitive and is composed of simple organic precursors, and the carbonate OM is more evolved and structurally complex.

The source(s) of the carbonate carbon in carbonaceous chondrites are organic compounds or other volatile species (e.g. $\mathrm{CH}_{4}, \mathrm{CO}, \mathrm{CO}_{2}$ ) in interstellar or protoplanetary ices, or, alternatively, organics that were oxidized (e.g., from reduced $\mathrm{C}$ to $\mathrm{CO}_{2}$ ) by radiationproduced peroxide when pre-accretionary ices melted (Cody and Alexander, 2005), which requires a generic correlation between the organic components in the two phases. Assuming that the alteration was in a closed system, Alexander et al. (2015) reported that with an initial abundance of water ice (10-20 wt $\%$ ), oxidation could have produced $0.07-0.13 \mathrm{wt} \% \mathrm{CO}_{2}$ in 
the parent body, which is in the range of $\mathrm{CM}$ carbonate carbon abundances. If the carbon was indeed derived from oxidation processes, formation of carbonate would be at the expense of carbon in OM, however, no clear inverse correlation between carbonate and organic abundances has been reported in the literature. The carbon isotopic variation between carbonates ( +25 to $+75 \%$ ) and IOM ( -30 to $-20 \%$ ) might indicate isotopic fractionation in the parent bodies or that the carbon in these materials were derived from isotopically different reservoirs (Alexander et al., 2015). On the contrary, soluble organic matter (extraterrestrial amino acids) and carbonates have more comparable carbon isotopic compositions $\left[\delta^{13} \mathrm{C}\right.$ of $\mathrm{CM}$ extraterrestrial amino acids $=+8$ to $+53 \%$ o (Pizzarello et al., 2004)]. Therefore, it is possible that the carbon of carbonate and SOM are derived from a similar source, and thus the formation of carbonate organics would be at the expense of carbon in matrix OM. Validation of the potential correlation between the meteoritic OM and the organics contained within the carbonate will require highly sensitive isotopic analysis on the OM extracted from the carbonate phase, which is deemed challenging in light of the current instrumental sensitivity.

Fig. 8 is a schematic diagram that describes the alteration history, the formation of the two generations of carbonate, and the synthesis of organic matter on the CM parent body. The heating regime occurred concurrently with or prior to parent body formation and synthesized simple organic precursor species such as hydrocarbons through processes like Fisher Tropsch type (FTT) mineral-catalyzed syntheses in the presence of $\mathrm{CO}, \mathrm{H}_{2}, \mathrm{NH}_{3}$ (Yoshino et al., 1971; Hayatsu and Anders, 1981). In agreement with this suggestion, the Raman parameters of the $\mathrm{OM}$ in the matrix are primitive and composed of highly-disordered carbons such as aromatic organic matter (Fig. 7). It is generally assumed that the source of water for aqueous alteration is water ice accreted with anhydrous precursor components (e.g., Grimm and 
McSween, 1989). Initial hydrous alteration began when ices melted as the parent body was heated during or after the parent body accretion with heat sources derived from in situ decay of radionuclides. Using $\mathrm{C}$ and $\mathrm{O}$ isotopic measurements, the carbonate formation temperatures were estimated to occur between 0 and $130^{\circ} \mathrm{C}$ (Guo and Eiler, 2007; Alexander et al., 2015). Aqueous alteration is often associated with hydrothermal processes and exothermic hydration reactions. The duration of post-hydration heating could have extended through these exothermic reactions, which is likely determined by the volume of aqueous fluid and thus the initial ice fraction of the parent body. The water would have been consumed by the hydration reactions, and served to buffer the increase in temperature achieved by the hydration processes (Cohen and Coker, 2000).

It has been suggested that aqueous alteration has little effect on the Raman parameters in meteorite matrix organics as the IOM is chemically inert and their aromatic moieties remain unaltered by aqueous processing (Cody and Alexander, 2005; Bonal et al., 2006; Busemann et al., 2007). The nature of $\boldsymbol{O M}$ in carbonate, however, shows a possible trend correlated to the degree of aqueous alteration, where the carbonate $\mathrm{OM}$ in the more aqueously-altered chondrites (e.g., Nogoya, Jbilet) have D band positions shifted to lower wavenumbers and narrower D \& G band widths (Fig. 7, Table 2). Our study also indicates that the CM samples display opposite aqueous and thermal alteration effects for the matrix OM (Extents of aqueous alteration, based on the nature of the carbonate: Nogoya > Jbilet > Murchison > WIS 91600; Extents of thermal metamorphism, based on the matrix OM maturity: WIS $91600>$ Santa Cruz > Murchison > Jbilet $>$ Nogoya).

Several hypotheses can be proposed based on these observations to describe the variation in the alteration extents experienced by different CM chondrites. (1) The more aqueously- 
altered CMs were derived from a water-rich region in the parent body, where the water occurred as a heat sink that buffered the heating process because water has a higher heat capacity than rock. (2) The CM parent body contained different lithologies with various volume fractions of anhydrous materials which could allow further exothermic hydration to take place (Brearley, 2006). (3) Localized heating events could have occurred that allowed carbonate precipitation to recommence with an evolved parent body aqueous fluid. This second heating regime could have been initiated by events such as impact that liberated heated fluids to circulate within a localized area, which is best represented by WIS 91600 which shows evidence of a shock event (Yabuta et al., 2010). $\mathrm{CO}_{2}$ degassing from the aqueous fluid via impact depressurization (Wilson et al., 1999) could produce carbonate in the presence of oxidized fluids. The more chemically evolved aqueous fluids could leach OM from the matrix, react with remaining anhydrous minerals, and further precipitate carbonates. This justifies the common conclusion drawn from this and various studies that the latter formed OM-bearing (type 2) carbonate is not present in all CM chondrites (e.g, Grady et al., 1988; Tyra et al., 2007; Tyra et al., 2012), and the OM-bearing carbonates were formed from more-evolved aqueous fluid than the OM-barren carbonate grains (type 1) (Tyra et al., 2012).

The initial aqueous activity that formed the first generation of carbonate could have involved highly oxidized fluids that led to the oxidation of OM and thus the production of the OMbarren carbonate. The aqueous activity ceased upon the termination of the heating event. A later short-term heating event, which could have possibly been caused by a localized impact event that led to $\mathrm{CO}_{2}$ degassing as well as thawing of ice, recreated a favorable condition for the second generation of carbonate to precipitate. While impact shock of ice is capable of synthesizing complex organic compounds (Martins et al., 2013), the associated aqueous event could also have synthesized other organic materials observed in carbonaceous chondrites 
(e.g., Bunch and Chang, 1980; Peltzer et al., 1984; Shock and Schulte, 1990). For instance, acetic acid can be produced in aqueous solution at the expense of organic precursors such as polycyclic aromatic hydrocarbons (PAHs), therefore carbonate and more evolved OM could coexist. This synthetic process releases hydrogen as a by-product (Yuen et al., 1984), eventually leading to a more acidic condition that was no longer favorable for carbonate precipitation. The stepwise formation of higher molecular weight compounds from simpler precursors is reflected by the correlation between the carbon isotopic values and the number of carbon in the molecule as the result of a kinetic isotope effect (Sephton and Gilmour, 2001). The organics trapped within the carbonates can be liberated only by the destruction of the carbonates, and thus carbonates provide an effective medium for preventing the decomposition of organic matter in meteorites until the host carbonate has dissolved.

Carbonates can be dated to constrain the timing and duration of post-accretion aqueous alteration of asteroid parent bodies (e.g., Macdougall et al., 1984; Endress et al., 1996; de Leuw et al., 2009; Petitat et al., 2011; Fujiya et al., 2012), thus an appropriate identification of carbonate for relative chronology is vital. However, the accuracy of $\mathrm{Mn} / \mathrm{Cr}$ dating to determine the ages of precipitation for secondary carbonates is complicated due to the uncertainties in carbonate $\mathrm{Mn} / \mathrm{Cr}$ relative sensitivity factors when carrying out the analysis with the secondary ion mass spectrometry (SIMS) technique (Jilly et al., 2014), lack of appropriate standards for SIMS (Sugiura et al., 2010), and the incomplete understanding of the formation chronology of different carbonates and their genetic relationships to secondary processes on parent bodies. As noted in Endress and Bischoff (1996), carbonates in CIs can occur in different forms, and only those which exist as large polycrystalline fragments between individual lithic clasts should be used for dating purposes as they are remnants of former carbonate veins that are not genetically linked to the lithological units in the meteorite. 
Although the OM-containing carbonates are generally larger in size, this trend is not consistent and thus the size and shape criteria do not provide a universal principle for the selection of carbonate grains in all chondritic classes. This also appears to be a major problem in many dating studies due to the limited sample availability. This situation might explain the wide range of estimated $\mathrm{Mn}-\mathrm{Cr}$ ages of carbonates in carbonaceous chondrites (Jilly et al., 2014).

\section{CONCLUSIONS}

We used Raman spectroscopy to investigate the organo-carbonate relationships in five CM chondrites: CM2.3 Jbilet Winselwan, CM2.5 Murchison, CM2.2 Nogoya, CM2 Santa Cruz, and CM2TII WIS 91600. Carbonates were identified by the distinctive Raman band in the $\sim 1100 \mathrm{~cm}^{-1}$ region that represents the symmetric stretching vibration mode $\left(v_{1}\right)$ of the $\left(\mathrm{CO}_{3}\right)^{2-}$ anion, as well as other minor vibration modes also attributed to the carbonate crystal structure. The analyzed carbonates present in the CMs are calcite, except for one dolomite grain in Nogoya. The presence of a complex carbonate composition in Nogoya suggests more progressive aqueous alteration, as compared to the other CM2s we examined. Typical firstorder D bands at $\sim 1350-1380 \mathrm{~cm}^{-1}$ and $\mathrm{G}$ band at $\sim 1580-1590 \mathrm{~cm}^{-1}$ were identified in the matrix of the meteorites. The broad D and G bands indicate the presence of amorphous carbon, yet only the carbonates of Jbilet, Nogoya, Santa Cruz and WIS 91600 display the D and $\mathrm{G}$ bands, implying that the carbonates might not have formed under equilibrium conditions from a single fluid. The carbonate OM shows an apparently higher degree of maturation compared to meteorite matrix $\mathrm{OM}$, indicating that the carbonate $\mathrm{OM}$ contains different organic components than the matrix OM. The initial aqueous activity that formed the first generation of carbonate could have involved highly oxidized fluids that led to the oxidation of $\mathrm{OM}$ and thus the production of the OM-barren carbonate. A later short-term 
heating event, which could have been triggered by impact heating, led to $\mathrm{CO}_{2}$ degassing and the circulation of more evolved aqueous fluids, recreated a favorable condition for the second generation of carbonate to precipitate with the presence of OM.

\section{ACKNOWLEDGEMENTS}

We thank the Arizona State University for the Nogoya sample, the Meteorite Working Group for the WIS 91600 sample, the Smithsonian Institution National Museum of Natural History for the Santa Cruz sample, and Richard Morris for the standard carbonate crystals. This study was supported by the NASA Cosmochemistry Program (MZ is the PI). QHSC acknowledges support from the NASA Postdoctoral Program at the Johnson Space Center, administered by Universities Space Research Association through a contract with NASA. We acknowledge Marc Fries for the helpful comments and discussions on the manuscript. We are also grateful for the advice given by Simon Clemett on the Raman curve-fitting procedures. We are very grateful to Pierre Beck (Assistant Editor), Hikaru Yabuta, Wataru Fujiya and an anonymous reviewer for their careful edits that significantly improved the manuscript.

\section{APPENDIX A. SUPPLEMENTARY DATA}

Supplementary data associated with this article can be found, in the online version, at XXXXXXXXXXXXXXXX. 


\section{REFERENCES}

Alexander, C.M.O.D., Fogel, M.L., Yabuta, H., Cody, G.D., (2007). The origin and evolution of chondrites recorded in the elemental and isotopic compositions of their macromolecular organic matter. Geochimica et Cosmochimica Acta 71, 4380-4403.

Alexander, C.M.O.D., Howard, K.T., Bowden, R., Fogel, M.L., (2013). The classification of $\mathrm{CM}$ and $\mathrm{CR}$ chondrites using bulk $\mathrm{H}, \mathrm{C}$ and $\mathrm{N}$ abundances and isotopic compositions.

Geochimica et Cosmochimica Acta 123, 244-260.

Alexander, C.M.O.D., Cody, G.D., Kebukawa, Y., Bowden, R., Fogel, M.L., Kilcoyne, A.L.D., Nittler, L.R., Herd, C.D.K., (2014). Elemental, isotopic, and structural changes in Tagish Lake insoluble organic matter produced by parent body processes. Meteoritics \& Planetary Science 49, 503-525.

Alexander, C.M.O.D., Bowden, R., Fogel, M.L., Howard, K.T., (2015). Carbonate abundances and isotopic compositions in chondrites. Meteoritics \& Planetary Science 50, 810-833.

Aoya, M., Kouketsu, Y., Endo, S., Shimizu, H., Mizukami, T., Nakamura, D., Wallis, S., (2010). Extending the applicability of the Raman carbonaceous-material geothermometer using data from contact metamorphic rocks. Journal of Metamorphic Geology 28, 895-914.

Barber, D.J., (1981). Matrix phyllosilicates and associated minerals in C2M carbonaceous chondrites. Geochimica et Cosmochimica Acta 45, 945-970.

Benedix, G.K., Leshin, L.A., Farquhar, J., Jackson, T., Thiemens, M.H., (2003). Carbonates in CM2 chondrites: constraints on alteration conditions from oxygen isotopic compositions and petrographic observations. Geochimica et Cosmochimica Acta 67, 1577-1588.

Beny-Bassez, C., Rouzaud, J., (1985). Characterization of carbonaceous materials by correlated electron and optical microscopy and Raman microspectroscopy. Scanning electron microscopy 1, 119-132.

Bernard, S., Beyssac, O., Benzerara, K., Findling, N., Tzvetkov, G., Brown Jr, G.E., (2010). XANES, Raman and XRD study of anthracene-based cokes and saccharose-based chars submitted to high-temperature pyrolysis. Carbon 48, 2506-2516.

Beyssac, O., Goffé, B., Chopin, C., Rouzaud, J.N., (2002a). Raman spectra of carbonaceous material in metasediments: a new geothermometer. Journal of Metamorphic Geology 20, 859-871.

Beyssac, O., Rouzaud, J.-N., Goffé, B., Brunet, F., Chopin, C., (2002b). Graphitization in a high-pressure, low-temperature metamorphic gradient: a Raman microspectroscopy and HRTEM study. Contributions to Mineralogy and Petrology 143, 19-31. 
Beyssac, O., Goffé, B., Petitet, J.-P., Froigneux, E., Moreau, M., Rouzaud, J.-N., (2003). On the characterization of disordered and heterogeneous carbonaceous materials by Raman spectroscopy. Spectrochimica Acta Part A: Molecular and Biomolecular Spectroscopy 59, 2267-2276.

Bischoff, W.D., Sharma, S.K., MacKenzie, F.T., (1985). Carbonate ion disorder in synthetic and biogenic magnesian calcites; a Raman spectral study. American Mineralogist 70, 581589.

Bonal, L., Quirico, E., Bourot-Denise, M., Montagnac, G., (2006). Determination of the petrologic type of CV3 chondrites by Raman spectroscopy of included organic matter. Geochimica et Cosmochimica Acta 70, 1849-1863.

Bonal, L., Bourot-Denise, M., Quirico, E., Montagnac, G., Lewin, E., (2007). Organic matter and metamorphic history of CO chondrites. Geochimica et Cosmochimica Acta 71, 16051623.

Bower, D.M., Steele, A., Fries, M.D., Kater, L., (2013). Micro Raman Spectroscopy of Carbonaceous Material in Microfossils and Meteorites: Improving a Method for Life Detection. Astrobiology 13, 103-113.

Brearley, A.J., Saxton, J.M., Lyon, I.C., Turner, G., (1999). Carbonates in the Murchison CM chondrite: CL characteristics and oxygen isotopic compositions, Lunar and Planetary Science Conference, p. 1301.

Brearley, A.J., (2006). The action of water. The University of Arizona Press, Tucson, AZ.

Browning, L.B., McSween Jr, H.Y., Zolensky, M.E., (1996). Correlated alteration effects in CM carbonaceous chondrites. Geochimica et Cosmochimica Acta 60, 2621-2633.

Bunch, T.E., Chang, S., (1980). Carbonaceous chondrites-II. Carbonaceous chondrite phyllosilicates and light element geochemistry as indicators of parent body processes and surface conditions. Geochimica et Cosmochimica Acta 44, 1543-1577.

Busemann, H., Alexander, M.O.D., Nittler, L.R., (2007). Characterization of insoluble organic matter in primitive meteorites by microRaman spectroscopy. Meteoritics \& Planetary Science 42, 1387-1416.

Caro, G.M.M., Matrajt, G., Dartois, E., Nuevo, M., d'Hendecourt, L., Deboffle, D., Montagnac, G., Chauvin, N., Boukari, C., Du, D.L., (2006). Nature and evolution of the dominant carbonaceous matter in interplanetary dust particles: effects of irradiation and identification with a type of amorphous carbon. $A \& A$ 459, 147-159.

Carter, P.W., Mitterer, R.M., (1978). Amino acid composition of organic matter associated with carbonate and non-carbonate sediments. Geochimica et Cosmochimica Acta 42, 12311238 . 
Castiglioni, C., Tommasini, M., Zerbi, G., (2004). Raman spectroscopy of polyconjugated molecules and materials: confinement effect in one and two dimensions. Philosophical Transactions of the Royal Society of London A: Mathematical, Physical and Engineering Sciences 362, 2425-2459.

Clemett, S., Messenger, S., Thomas-Keprta, K., Nakamura-Messenger, K., (2012). The Spatial Distribution of Organic Matter and Mineralogical Relationships in Carbonaceous Chondrites.

Cloots, R., (1991). Raman spectrum of carbonates MIICO3 in the 1100-1000cm -1 region: observation of the $v 1$, mode of the isotopic (C16O182O)2- ion. Spectrochimica Acta Part A: Molecular Spectroscopy 47, 1745-1750.

Cody, G.D., Alexander, C.M.O.D., (2005). NMR studies of chemical structural variation of insoluble organic matter from different carbonaceous chondrite groups. Geochimica et Cosmochimica Acta 69, 1085-1097.

Cohen, B.A., Coker, R.F., (2000). Modeling of Liquid Water on CM Meteorite Parent Bodies and Implications for Amino Acid Racemization. Icarus 145, 369-381.

Cooney, T.F., Scott, E.R.D., Krot, A.N., Sharma, S.K., Yamaguchi, A., (1999). Vibrational spectroscopic study of minerals in the Martian meteorite ALH 84001. American Mineralogist 84, 1569-1576.

Cronin, J.R., Pizzarello, S., (1997). Enantiomeric Excesses in Meteoritic Amino Acids. Science 275, 951-955.

de Leuw, S., Rubin, A.E., Schmitt, A.K., Wasson, J.T., (2009). 53Mn-53Cr systematics of carbonates in CM chondrites: Implications for the timing and duration of aqueous alteration. Geochimica et Cosmochimica Acta 73, 7433-7442.

de Leuw, S., Rubin, A.E., Wasson, J.T., (2010). Carbonates in CM chondrites: Complex formational histories and comparison to carbonates in CI chondrites. Meteoritics \& Planetary Science 45, 513-530.

Doyle, P.M., Jogo, K., Nagashima, K., Krot, A.N., Wakita, S., Ciesla, F.J., Hutcheon, I.D., (2015). Early aqueous activity on the ordinary and carbonaceous chondrite parent bodies recorded by fayalite. Nat Commun $\mathbf{6}$.

Endress, M., Bischoff, A., (1996). Carbonates in CI chondrites: Clues to parent body evolution. Geochimica et Cosmochimica Acta 60, 489-507.

Endress, M., Zinner, E., Bischoff, A., (1996). Early aqueous activity on primitive meteorite parent bodies. Nature 379, 701-703. 
Ferrari, A.C., Robertson, J., (2000). Interpretation of Raman spectra of disordered and amorphous carbon. Physical Review B 61, 14095-14107.

Ferrari, A.C., Robertson, J., (2004). Raman spectroscopy of amorphous, nanostructured, diamond-like carbon, and nanodiamond. Philosophical Transactions of the Royal Society of London A: Mathematical, Physical and Engineering Sciences 362, 2477-2512.

Fredriksson, K., Kerridge, J.F., (1988). Carbonates and sulfates in CI chondrites-formation by aqueous activity on the parent body. Meteoritics 23, 35-44.

Fries, M., Burchell, M., Kearsley, A., Steele, A., (2009). Capture effects in carbonaceous material: A Stardust analogue study. Meteoritics \& Planetary Science 44, 1465-1474.

Fries, M., Bhartia, R., Steele, A., (2011). Carbonaceous chondrite groups discerned using Raman spectral parameters, Lunar and Planetary Science Conference, p. 1860.

Fries, M., Steele, A., (2011). Raman Spectroscopy and Confocal Raman Imaging in Mineralogy and Petrography, in: Dieing, T., Hollricher, O., Toporski, J. (Eds.), Confocal Raman Microscopy. Springer Berlin Heidelberg, pp. 111-135.

Fujiya, W., Sugiura, N., Hotta, H., Ichimura, K., Sano, Y., (2012). Evidence for the late formation of hydrous asteroids from young meteoritic carbonates. Nat Commun 3, 627.

Glavin, D.P., Elsila, J.E., Burton, A.S., Callahan, M.P., Dworkin, J.P., Hilts, R.W., Herd, C.D.K., (2012). Unusual nonterrestrial 1-proteinogenic amino acid excesses in the Tagish Lake meteorite. Meteoritics \& Planetary Science 47, 1347-1364.

Golden, D., Ming, D., Schwandt, C., Lauer, H., Socki, R., Morris, R., Lofgren, G., McKay, G., (2001). A simple inorganic process for formation of carbonates, magnetite, and sulfides in Martian meteroite ALH84001 (vol 86, pg 370, 2001). American Mineralogist 86, 956-956.

Grady, M., Abernethy, F., Verchovsky, A., King, A., Schofield, P., Russell, S., (2014). The Jbilet Winselwan Carbonaceous Chondrite 2. Light Element Geochemistry: Strengthening the Link Between CM and CO Meteorites? LPI Contributions 1800, 5377.

Grady, M.M., Wright, I.P., Swart, P.K., Pillinger, C.T., (1988). The carbon and oxygen isotopic composition of meteoritic carbonates. Geochimica et Cosmochimica Acta 52, 28552866.

Grimm, R.E., McSween, H.Y., (1989). Water and the thermal evolution of carbonaceous chondrite parent bodies. Icarus 82, 244-280.

Gunasekaran, S., Anbalagan, G., Pandi, S., (2006). Raman and infrared spectra of carbonates of calcite structure. Journal of Raman Spectroscopy 37, 892-899. 
Guo, W., Eiler, J.M., (2007). Temperatures of aqueous alteration and evidence for methane generation on the parent bodies of the CM chondrites. Geochimica et Cosmochimica Acta 71, $5565-5575$.

Hashiguchi, M., Yurimoto, H., (2016). Hydrogen Isotopic Compositions and Chemical Structures of Organic Materials in Northwest Africa 801 CR2 Chondrite: Implications for Metamorphism Histories of Extraterrestrial Organic Materials, Lunar and Planetary Science Conference, p. 1216.

Hayatsu, R., Anders, E., (1981). Organic compounds in meteorites and their origins, Cosmoand Geochemistry. Springer Berlin Heidelberg, pp. 1-37.

Homma, Y., Kouketsu, Y., Kagi, H., Mikouchi, T., Yabuta, H., (2015). Raman spectroscopic thermometry of carbonaceous material in chondrites: four-band fitting analysis and expansion of lower temperature limit. Journal of Mineralogical and Petrological Sciences 110, 276-282.

Huss, G.R., Rubin, A.E., Grossman, J.N., (2006). Thermal metamorphism in chondrites, in: Lauretta, D.S., McSween, H.J.J. (Eds.), Meteorites and the early solar system II. The University of Arizona Press, Tucson, AZ, pp. 567-586.

Hutcheon, I., Weisberg, M., Phinney, D., Zolensky, M., Prinz, M., Ivanov, A., (1999). Radiogenic 53Cr in Kaidun carbonates: Evidence for very early aqueous activity, Lunar and Planetary Science Conference, p. 1722.

Jilly, C.E., Huss, G.R., Krot, A.N., Nagashima, K., Yin, Q.-Z., Sugiura, N., (2014). 53Mn$53 \mathrm{Cr}$ dating of aqueously formed carbonates in the CM2 lithology of the Sutter's Mill carbonaceous chondrite. Meteoritics \& Planetary Science 49, 2104-2117.

Johnson, C.A., Prinz, M., (1993). Carbonate compositions in CM and CI chondrites and implications for aqueous alteration. Geochimica et Cosmochimica Acta 57, 2843-2852.

Kouketsu, Y., Mizukami, T., Mori, H., Endo, S., Aoya, M., Hara, H., Nakamura, D., Wallis, S., (2014). A new approach to develop the Raman carbonaceous material geothermometer for low-grade metamorphism using peak width. Island Arc 23, 33-50.

Lahfid, A., Beyssac, O., Deville, E., Negro, F., Chopin, C., Goffé, B., (2010). Evolution of the Raman spectrum of carbonaceous material in low-grade metasediments of the Glarus Alps (Switzerland). Terra Nova 22, 354-360.

Lancet, M.S., Anders, E., (1970). Carbon Isotope Fractionation in the Fischer-Tropsch Synthesis and in Meteorites. Science 170, 980-982.

Lee, M.R., Sofe, M.R., Lindgren, P., Starkey, N.A., Franchi, I.A., (2013). The oxygen isotope evolution of parent body aqueous solutions as recorded by multiple carbonate generations in 
the Lonewolf Nunataks 94101 CM2 carbonaceous chondrite. Geochimica et Cosmochimica Acta 121, 452-466.

Lee, M.R., Lindgren, P., Sofe, M.R., (2014). Aragonite, breunnerite, calcite and dolomite in the $\mathrm{CM}$ carbonaceous chondrites: High fidelity recorders of progressive parent body aqueous alteration. Geochimica et Cosmochimica Acta 144, 126-156.

Macdougall, J., Lugmair, G., Kerridge, J., (1984). Early aqueous activity on primitive meteorite parent bodies. Nature 307, 249-251.

Martins, Z., Price, M.C., Goldman, N., Sephton, M.A., Burchell, M.J., (2013). Shock synthesis of amino acids from impacting cometary and icy planet surface analogues. Nature Geoscience.

Maslova, O.A., Ammar, M.R., Guimbretière, G., Rouzaud, J.N., Simon, P., (2012).

Determination of crystallite size in polished graphitized carbon by Raman spectroscopy. Physical Review B 86, 134205.

Matrajt, G., Borg, J., Raynal, P.I., Djouadi, Z., d'Hendecourt, L., Flynn, G., Deboffle, D., (2004). FTIR and Raman analyses of the Tagish Lake meteorite: Relationship with the aliphatic hydrocarbons observed in the Diffuse Interstellar Medium. $A \& A$ 416, 983-990.

McSween, H.Y., Jr., (1979). Are carbonaceous chondrites primitive or processed? A review. Rev. Geophys. 17, 1059-1078.

Meier, R.J., (2005). On art and science in curve-fitting vibrational spectra. Vibrational spectroscopy 39, 266-269.

Nakamura, T., (2005). Post-hydration thermal metamorphism of carbonaceous chondrites. $J$. Mineral. Petrol. Sci. 100.

Nakato, A., Nakamura, T., Noguchi, T., (2009). Mineralogical and chemical variations recorded in dehydrated carbonaceous chondrites. Meteoritics and Planetary Science Supplement 72, 5336.

Nemanich, R.J., Solin, S.A., (1979). First- and second-order Raman scattering from finitesize crystals of graphite. Physical Review B 20, 392-401.

Pasteris, J.D., (1989). In Situ Analysis in Geological Thin-Sections by Laser Raman Microprobe Spectroscopy: A Cautionary Note. Applied Spectroscopy 43, 567-570.

Peltzer, E.T., Bada, J.L., Schlesinger, G., Miller, S.L., (1984). The chemical conditions on the parent body of the murchison meteorite: Some conclusions based on amino, hydroxy and dicarboxylic acids. Advances in Space Research 4, 69-74. 
Pernet-Fisher, J., Howarth, G., Barry, P., Bodnar, R., Taylor, L., (2014). The Extent of Aqueous Alteration Within the Jbilet Winselwan CM2 Chondrite, Lunar and Planetary Institute Science Conference Abstracts, p. 2386.

Petitat, M., Marrocchi, Y., McKeegan, K.D., Mostefaoui, S., Meibom, A., Zolensky, M.E., Gounelle, M., (2011). 53Mn-53Cr ages of Kaidun carbonates. Meteoritics \& Planetary Science 46, 275-283.

Pizzarello, S., Huang, Y., Fuller, M., (2004). The carbon isotopic distribution of Murchison amino acids. Geochimica et Cosmochimica Acta 68, 4963-4969.

Quirico, E., Raynal, P.-I., Bourot-Denise, M., (2003). Metamorphic grade of organic matter in six unequilibrated ordinary chondrites. Meteoritics \& Planetary Science 38, 795-811.

Quirico, E., Borg, J., Raynal, P.-I., Montagnac, G., d'Hendecourt, L., (2005a). A microRaman survey of 10 IDPs and 6 carbonaceous chondrites. Planetary and Space Science 53, 1443-1448.

Quirico, E., Rouzaud, J.-N., Bonal, L., Montagnac, G., (2005b). Maturation grade of coals as revealed by Raman spectroscopy: Progress and problems. Spectrochimica Acta Part A: Molecular and Biomolecular Spectroscopy 61, 2368-2377.

Quirico, E., Bourot-Denise, M., Bonal, L., Orthous-Daunay, F.-R., Beck, P., Montagnac, G., (2009a). Structural and chemical characterization of the organic matter in metamorphosed CM carbonaceous chondrites. Meteoritics and Planetary Science Supplement 72, 5208.

Quirico, E., Montagnac, G., Rouzaud, J.N., Bonal, L., Bourot-Denise, M., Duber, S., Reynard, B., (2009b). Precursor and metamorphic condition effects on Raman spectra of poorly ordered carbonaceous matter in chondrites and coals. Earth and Planetary Science Letters 287, 185-193.

Quirico, E., Bourot-denise, M., Robin, C., Montagnac, G., Beck, P., (2011). A reappraisal of the metamorphic history of EH3 and EL3 enstatite chondrites. Geochimica et Cosmochimica Acta 75, 3088-3102.

Quirico, E., Orthous-Daunay, F.-R., Beck, P., Bonal, L., Brunetto, R., Dartois, E., Pino, T., Montagnac, G., Rouzaud, J.-N., Engrand, C., Duprat, J., (2014). Origin of insoluble organic matter in type 1 and 2 chondrites: New clues, new questions. Geochimica et Cosmochimica Acta 136, 80-99.

Rahl, J.M., Anderson, K.M., Brandon, M.T., Fassoulas, C., (2005). Raman spectroscopic carbonaceous material thermometry of low-grade metamorphic rocks: Calibration and application to tectonic exhumation in Crete, Greece. Earth and Planetary Science Letters 240, 339-354. 
Riciputi, L.R., McSween Jr, H.Y., Johnson, C.A., Prinz, M., (1994). Minor and trace element concentrations in carbonates of carbonaceous chondrites, and implications for the compositions of coexisting fluids. Geochimica et Cosmochimica Acta 58, 1343-1351.

Rubin, A., Trigo-Rodriguez, J., Wasson, J., (2005). A New Aqueous Alteration Index for CM Carbonaceous Chondrites. Meteoritics and Planetary Science Supplement 40, 5050.

Rubin, A.E., Trigo-Rodríguez, J.M., Huber, H., Wasson, J.T., (2007). Progressive aqueous alteration of CM carbonaceous chondrites. Geochimica et Cosmochimica Acta 71, 2361-2382.

Scott, E.R.D., Yamaguchi, A., Krot, A.N., (1997). Petrological evidence for shock melting of carbonates in the martian meteorite ALH84001. Nature 387, 377-379.

Sephton, M.A., Gilmour, I., (2001). Compound-specific isotope analysis of the organic constituents in carbonaceous chondrites. Mass Spectrometry Reviews 20, 111-120.

Sephton, M.A., Verchovsky, A.B., Bland, P.A., Gilmour, I., Grady, M.M., Wright, I.P., (2003). Investigating the variations in carbon and nitrogen isotopes in carbonaceous chondrites. Geochimica et Cosmochimica Acta 67, 2093-2108.

Shock, E.L., Schulte, M.D., (1990). Amino-acid synthesis in carbonaceous meteorites by aqueous alteration of polycyclic aromatic hydrocarbons. Nature 343, 728-731.

Smith, J., Kaplan, I., (1970). Endogenous carbon in carbonaceous meteorites. Science 167, 1367-1370.

Steele, A., McCubbin, F.M., Fries, M.D., Golden, D.C., Ming, D.W., Benning, L.G., (2012). Graphite in the martian meteorite Allan Hills 84001. American Mineralogist 97, 1256-1259.

Suess, E., (1970). Interaction of organic compounds with calcium carbonate-I. Association phenomena and geochemical implications. Geochimica et Cosmochimica Acta 34, 157-168.

Suess, E., (1973). Interaction of organic compounds with calcium carbonate-II. Organocarbonate association in Recent sediments. Geochimica et Cosmochimica Acta 37, 2435-2447.

Sugiura, N., Ichimura, K., Fujiya, W., Takahata, N., (2010). Mn/Cr relative sensitivity factors for synthetic calcium carbonate measured with a NanoSIMS ion microprobe. Geochemical Journal 44, e11-e16.

Sun, J., Wu, Z., Cheng, H., Zhang, Z., Frost, R.L., (2014). A Raman spectroscopic comparison of calcite and dolomite. Spectrochimica Acta Part A: Molecular and Biomolecular Spectroscopy 117, 158-162.

Thomas-Keprta, K.L., Clemett, S.J., Messenger, S., Ross, D.K., Le, L., Rahman, Z., McKay, D.S., Gibson Jr, E.K., Gonzalez, C., Peabody, W., (2014). Organic matter on the Earth's Moon. Geochimica et Cosmochimica Acta 134, 1-15. 
Thomas, M.M., Clouse, J.A., Longo, J.M., (1993). Adsorption of organic compounds on carbonate minerals: 1 . Model compounds and their influence on mineral wettability. Chemical Geology 109, 201-213.

Tonui, E., Zolensky, M., Hiroi, T., Wang, M.-S., Lipschutz, M., (2002). Petrographic, chemical and spectroscopic data on thermally metamorphosed carbonaceous chondrites, Lunar and Planetary Science Conference, p. 1288.

Tonui, E., Zolensky, M., Hiroi, T., Nakamura, T., Lipschutz, M.E., Wang, M.-S., Okudaira, K., (2014). Petrographic, chemical and spectroscopic evidence for thermal metamorphism in carbonaceous chondrites I: CI and CM chondrites. Geochimica et Cosmochimica Acta 126, 284-306.

Tuinstra, F., Koenig, J.L., (1970a). Characterization of Graphite Fiber Surfaces with Raman Spectroscopy. Journal of Composite Materials 4, 492-499.

Tuinstra, F., Koenig, J.L., (1970b). Raman Spectrum of Graphite. The Journal of Chemical Physics 53, 1126-1130.

Tyra, M.A., Farquhar, J., Wing, B.A., Benedix, G.K., Jull, A.J.T., Jackson, T., Thiemens, M.H., (2007). Terrestrial alteration of carbonate in a suite of Antarctic CM chondrites: Evidence from oxygen and carbon isotopes. Geochimica et Cosmochimica Acta 71, 782-795.

Tyra, M.A., Farquhar, J., Guan, Y., Leshin, L.A., (2012). An oxygen isotope dichotomy in CM2 chondritic carbonates-A SIMS approach. Geochimica et Cosmochimica Acta 77, 383395.

Van Schmus, W.R., Wood, J.A., (1967). A chemical-petrologic classification lot the chondritic meteorites. Geochimica et Cosmochimica Acta 31, 747-765.

Wang, Y., Alsmeyer, D.C., McCreery, R.L., (1990). Raman spectroscopy of carbon materials: structural basis of observed spectra. Chemistry of Materials 2, 557-563.

Weisberg, M.K., McCoy, T.J., Krot, A.N., (2006). Systematics and Evaluation of Meteorite Classification, in: Lauretta, D.S., McSween, H.Y. (Eds.), Meteorites and the Early Solar System II. Univ. Arizona press, pp. 19-52.

Wilson, L., Keil, K., Browning, L.B., Krot, A.N., Bourcier, W., (1999). Early aqueous alteration, explosive disruption, and reprocessing of asteroids. Meteoritics \& Planetary Science 34, 541-557.

Wopenka, B., Pasteris, J.D., (1993). Structural characterization of kerogens to granulitefacies graphite: applicability of Raman microprobe spectroscopy. The American Mineralogist 78, 533-557. 
Yabuta, H., Alexander, C.M.O.D., Fogel, M.L., Kilcoyne, A.L.D., Cody, G.D., (2010). A molecular and isotopic study of the macromolecular organic matter of the ungrouped C2 WIS 91600 and its relationship to Tagish Lake and PCA 91008. Meteoritics \& Planetary Science 45, 1446-1460.

Yoshino, D., Hayatsu, K., Anders, E., (1971). Origin of organic matter in early solar system-III. Amino acids: Catalytic synthesis. Geochimica et Cosmochimica Acta 35, 927 938.

Yuen, G., Blair, N., Des Marais, D.J., Chang, S., (1984). Carbon isotope composition of low molecular weight hydrocarbons and monocarboxylic acids from Murchison meteorite. Nature 307, 252-254.

Zolensky, M., Ivanov, A., (2003). The Kaidun Microbreccia Meteorite: A Harvest from the Inner and Outer Asteroid Belt. Chemie der Erde - Geochemistry 63, 185-246.

Zolensky, M., Mikouchi, T., Hagiya, K., Ohsumi, K., Komatsu, M., Le, L., (2015). Evidence for impact shock melting in CM and CI chondrite regolith samples, Lunar and Planetary Science Conference, p. 2261.

Zolensky, M.E., Mittlefehldt, D.W., Lipschutz, M.E., Wang, M.-S., Clayton, R.N., Mayeda, T.K., Grady, M.M., Pillinger, C., B, D., (1997). CM chondrites exhibit the complete petrologic range from type 2 to 1. Geochimica et Cosmochimica Acta 61, 5099-5115. 


\section{FIGURE CAPTIONS}

Fig. 1. Photomicrograph of calcite under crossed polars. Characteristic calcite twinning is evident.

Fig. 2. A, Photomicrographs taken in visible light showing the analyzed spots (marked by the crosshairs) of the carbonate standards (aragonite, calcite, dolomite and siderite) before and after irradiation. The acquisition parameters are described in the experimental apparatus section. Laser beam damage was only observed for siderite, which is indicated by the arrow in the close-up images marked by the boxes. B, Representative raw Raman spectra of the carbonate standards.

Fig. 3. Comparison between the fitting results of different curve fitting models. Coefficient of determination $\left(\mathrm{r}^{2}\right)$ values of the models are: Lorentzian + BWF: 0.9877; 2 Voigt: $0.9854 ; 2$ Lorentzian: 0.9877; 2 Gaussian: 0.9797; 5 Lorentzian (one G and four D bands): 0.9985.

Fig. 4. Peak-fitting results obtained with pure Lorentzian profiles in the first-order region (1000 to $1800 \mathrm{~cm}^{-1}$ ) of Jbilet showing the contributions of the C, G, and D1-D4 bands to the total spectrum. (O): Background-corrected data. Black solid line: Peak-fitting result. C: calcite; G: graphite band; D1-D4: disordered (defect-activated) bands.

Fig. 5. Raman spectra showing the first-order regions of the carbonates in the CMs. The positions of the CM carbonate peaks are compared to calcite (red) and dolomite (blue) standards at $\sim 160,285,715$, and $1090 \mathrm{~cm}^{-1}$. The peak positions of Nogoya (Grain 5) clearly match with the Raman peaks of dolomite. 
Fig. 6. Representative Raman spectra (250 to $2000 \mathrm{~cm}^{-1}$ region) of the carbonate (black solid line), the crystal boundary of the carbonate (blue dashed line) and the matrix (red solid line) of Jbilet, Murchison, WIS 91600, and Nogoya. The corresponding Raman spot locations of the spectra are shown in the photomicrograph (scale bar is $40 \mu \mathrm{m}$ ). The size of the Raman spot location is not to scale and is shown at the current scale for legibility (the actual Raman probe spot size was $\sim 1.14 \mu \mathrm{m}$ ). The plots on the left (Jbilet and WIS 91600) clearly display the broad D and $\mathrm{G}$ bands within the carbonate, boundary and matrix, but the D and G bands are not observed for the carbonate for the plots on the right (Murchison and Nogoya).

Fig. 7. Raman peak parameters (Full width half-maximum $[\Gamma]$ and peak positions $[\omega]$ of $D$ and $\mathrm{G}$ bands, and the $\mathrm{D} / \mathrm{G}$ peak intensity $\left[\mathrm{I}_{\mathrm{D}} / \mathrm{I}_{\mathrm{G}}\right]$ ratios $[\mathrm{R} 1$ ratios $]$ ) of selected spectra of the

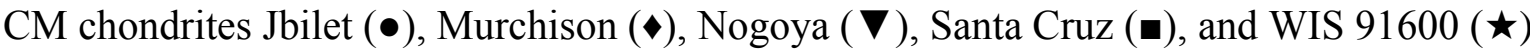
in this study. A, $\Gamma_{\mathrm{D}}$ against $\Gamma_{\mathrm{G}} . \mathbf{B}, \mathrm{G}$ band parameters. $\mathbf{C}, \mathrm{D}$ band parameters. D, R1 ratios against $\Gamma_{\mathrm{D}}$. Blue markers $-\mathrm{OM}$ in matrix; Red markers $-\mathrm{OM}$ in carbonate. The low coefficient of determination $\left(\mathrm{R}^{2}\right)$ value $(0.408)$ of the data in plot $\mathrm{C}$ indicates that the correlation between the D parameters is weak. (*) The data of WIS 91600 carbonate are not considered when calculating the $\mathrm{R}^{2}$ value for the data in plot $\mathrm{B}$.

Fig. 8. Schematic representation of the carbonate formation process and the thermal alteration regimes experienced by the CM parent body. 


\section{TABLE CAPTIONS}

Table 1. Raman peak positions and the corresponding assignments of the carbonate bands of the CM2 samples, and calcite and dolomite standards. ${ }^{\mathrm{a}}$

Table 2. Carbonates and matrix of CM2 meteorite samples, classification, Raman peak parameters, coefficient of determination $\left(\mathrm{r}^{2}\right)$ values of the peak-fitting result, and the calculated peak metamorphic temperatures (PMT). ${ }^{a}$ 


\section{Tables}

2 Article title: Investigation of organo-carbonate associations in carbonaceous chondrites by Raman spectroscopy

3 Authors: Queenie H. S. Chan ${ }^{\mathrm{a}, *}$, Michael E. Zolensky ${ }^{\mathrm{a}}$, Robert. J. Bodnar ${ }^{\mathrm{b}}$, Charles Farley ${ }^{\mathrm{b}}$, and Jacob C. H. Cheung ${ }^{\mathrm{c}}$

5 Table 1. Peak positions and the corresponding assignments of the carbonate bands of the CM2 samples, calcite and dolomite standards. ${ }^{\text {a }}$

\begin{tabular}{|c|c|c|c|c|c|c|c|c|c|c|c|c|c|c|c|c|c|c|c|}
\hline \multicolumn{20}{|c|}{$\operatorname{Raman} \omega\left(\mathrm{cm}^{-1}\right)$} \\
\hline \multicolumn{3}{|c|}{ Jbilet } & \multicolumn{3}{|c|}{ Murchison } & \multicolumn{3}{|c|}{$\begin{array}{l}\text { Nogoya } \\
\text { (Grain 1) }\end{array}$} & \multicolumn{3}{|c|}{$\begin{array}{c}\text { Nogoya } \\
\text { (Grain 5) }\end{array}$} & \multicolumn{3}{|c|}{ SantaCruz } & \multicolumn{2}{|c|}{ WIS 91600} & \multirow{2}{*}{$\begin{array}{c}\text { Calcite } \\
156\end{array}$} & \multirow{2}{*}{$\begin{array}{c}\text { Dolomite } \\
176\end{array}$} & \multirow{2}{*}{\begin{tabular}{l}
\multicolumn{1}{c}{ Assignments $^{\mathbf{b}}$} \\
Translational \\
$\left(\mathrm{Ca}, \mathrm{CO}_{3},(\mathrm{Mg})\right)$
\end{tabular}} \\
\hline 158 & \pm & 0.1 & 157 & \pm & 0.5 & 157 & \pm & 0.3 & 177 & \pm & 0.3 & 157 & \pm & 0.1 & & c & & & \\
\hline 285 & \pm & 0.3 & 283 & \pm & 0.8 & 284 & \pm & 0.4 & 300 & \pm & 0.6 & 284 & \pm & 0.3 & 284 & \pm 1.1 & 282 & 299 & $\begin{array}{l}\text { Translational } \\
\left(\mathrm{Ca}, \mathrm{CO}_{3},(\mathrm{Mg})\right)\end{array}$ \\
\hline 716 & \pm & 0.3 & 715 & \pm & 0.1 & 716 & \pm & 0.0 & 726 & \pm & 1.1 & 715 & \pm & 0.4 & & c & 712 & 724 & $\begin{array}{l}v_{4} \text {-Symmetric } \mathrm{CO}_{3} \\
\text { deformation }\end{array}$ \\
\hline & $\mathrm{c}$ & & & $\mathrm{c}$ & & & $\mathrm{c}$ & & & $\mathrm{c}$ & & & $\mathrm{c}$ & & & c & 1436 & 1441 & $\begin{array}{l}v_{3} \text {-Symmetric } \mathrm{CO}_{3} \\
\text { deformation }\end{array}$ \\
\hline & $\mathrm{c}$ & & & $\mathrm{c}$ & & & $\mathrm{c}$ & & & $c$ & & & $\mathrm{c}$ & & & c & 1750 & $\mathrm{c}$ & $v_{1}+v_{4}$ \\
\hline
\end{tabular}

${ }^{\mathrm{a}}$ Peak centers $(\omega)$ were obtained using a Lorentzian profile for curve fitting, see text. Uncertainties are $1 \sigma$ standard deviation of the mean.

${ }^{\mathrm{b}}$ Raman band assignments are given by Gunasekaran et al. 2006.

${ }^{\mathrm{c}}$ The peak intensity is too low for accurate determination of the peak position.

Tables - Page 1 of 2 
6 Table 2. Carbonates and matrix of CM2 meteorite samples, classification, Raman peak parameters, coefficient of determination $\left(\mathrm{r}^{2}\right)$ values of the

7 peak-fitting result, and the calculated peak metamorphic temperatures (PMT). ${ }^{\text {a }}$

\begin{tabular}{|c|c|c|c|c|c|c|c|c|c|}
\hline Class & Samples & $\mathbf{C} / \mathbf{M}^{\mathbf{b}}$ & $\omega_{G}\left(\mathrm{~cm}^{-1}\right)$ & $\omega_{\mathrm{D}}\left(\mathrm{cm}^{-1}\right)$ & $\Gamma_{\mathrm{G}}\left(\mathrm{cm}^{-1}\right)$ & $\Gamma_{\mathrm{D}}\left(\mathbf{c m}^{-1}\right)$ & $\mathbf{I}_{\mathbf{D}} / \mathbf{I}_{\mathbf{G}}{ }^{\mathbf{c}}$ & PMT $\left({ }^{\circ} \mathbf{C}\right)$ & $\begin{array}{l}\mathbf{L}_{a} \\
(\mathbf{n m})\end{array}$ \\
\hline CM2.3 & Jbilet & M & $1589.1 \pm 0.8$ & $1378.7 \pm 0.8$ & $111.7 \pm 1.3$ & $379.1 \pm 2.6$ & $1.074 \pm 0.082$ & $305.5 \pm 4.7$ & 1.40 \\
\hline CM2.7 & & M & $1587.3 \pm 0.4$ & $1377 \pm 1.1$ & $114.4 \pm 1.1$ & $381 \pm 3.4$ & $1.089 \pm 0.02$ & $309.2 \pm 6.3$ & 1.41 \\
\hline \multirow[t]{2}{*}{ CM2.2 } & \multirow[t]{2}{*}{ Nogoya } & $\mathrm{C}$ & $1599.3 \pm 0.4$ & $1376.4 \pm 3.6$ & $80.7 \pm 2.7$ & $324 \pm 16$ & $1.043 \pm 0.074$ & $238.5 \pm 14.9$ & 1.38 \\
\hline & & M & $1588.3 \pm 0.7$ & $1377.3 \pm 2.1$ & $113 \pm 4.1$ & $368.7 \pm 9.4$ & $1.069 \pm 0.037$ & $291.7 \pm 15.2$ & 1.39 \\
\hline \multirow[t]{2}{*}{ CM2TII } & \multirow[t]{2}{*}{ WIS 91600} & $\mathrm{C}$ & $1597.2 \pm 0.4$ & $1380 \pm 0$ & $120.1 \pm 1.4$ & $346.7 \pm 3.6$ & $1.047 \pm 0.014$ & $257.4 \pm 4.8$ & 1.38 \\
\hline & & M & $1588.4 \pm 0.9$ & $1377 \pm 3$ & $108.1 \pm 6.5$ & $405.1 \pm 21.9$ & $1.191 \pm 0.037$ & $362.7 \pm 49.8$ & 1.47 \\
\hline
\end{tabular}

${ }^{\mathrm{a}}$ The Raman peak parameters were calculated after peak deconvolution using a two Lorentzian profiles peak-fitting model. Estimated PMTs were calculated based the geothermometer given by Busemann et al. (2007).

${ }^{\mathrm{b}} \mathrm{C} / \mathrm{M}$ : C - Carbonate; M - Matrix

${ }^{\mathrm{c}}$ Peak intensity (I): band height from the Lorentzian fitting parameters above background.

n.a. Not applicable. $\mathrm{D}$ and $\mathrm{G}$ bands were not detected.

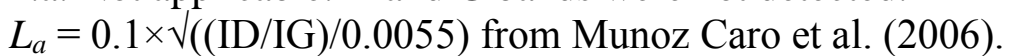

The uncertainties are the standard error of the mean of all used spectra. 


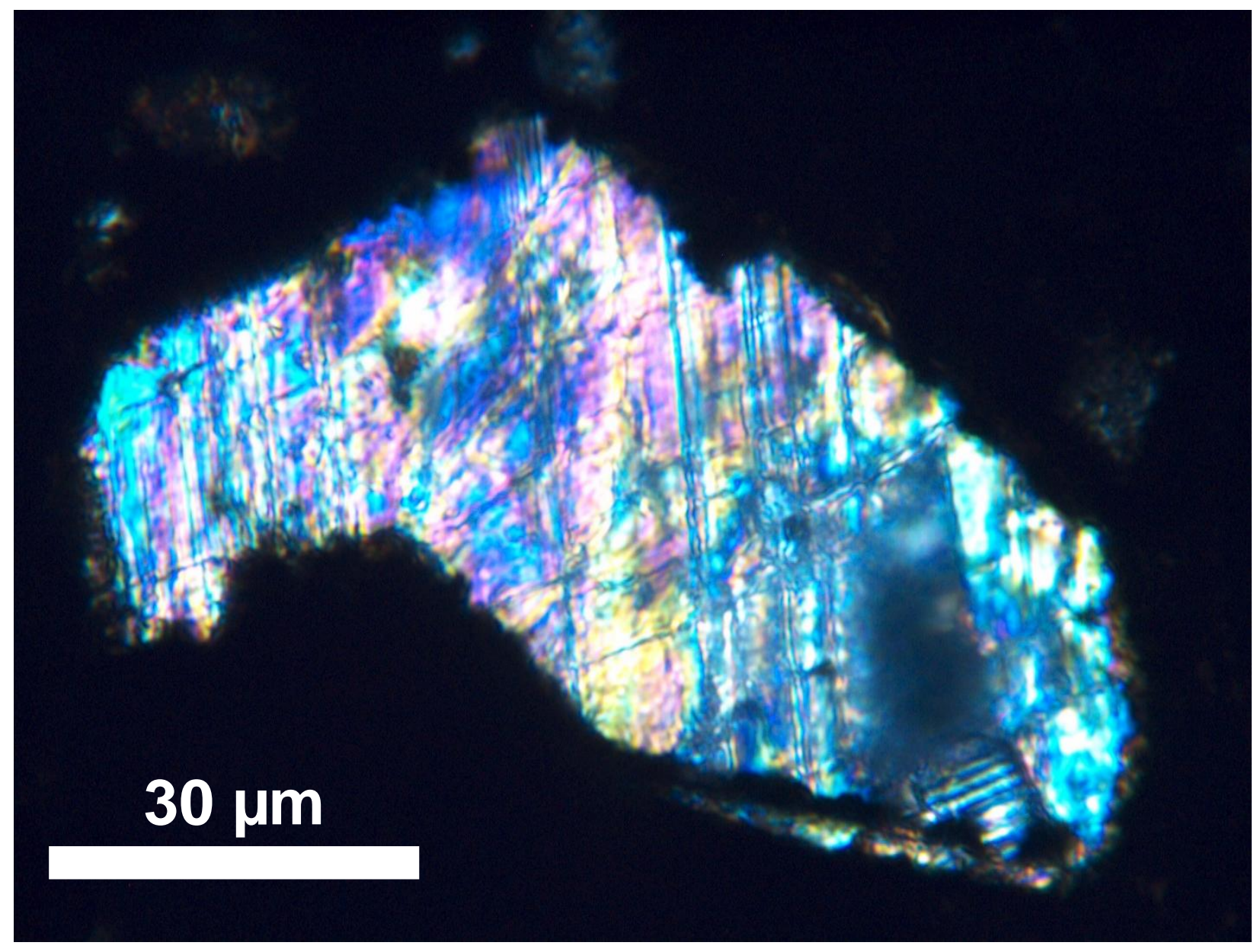




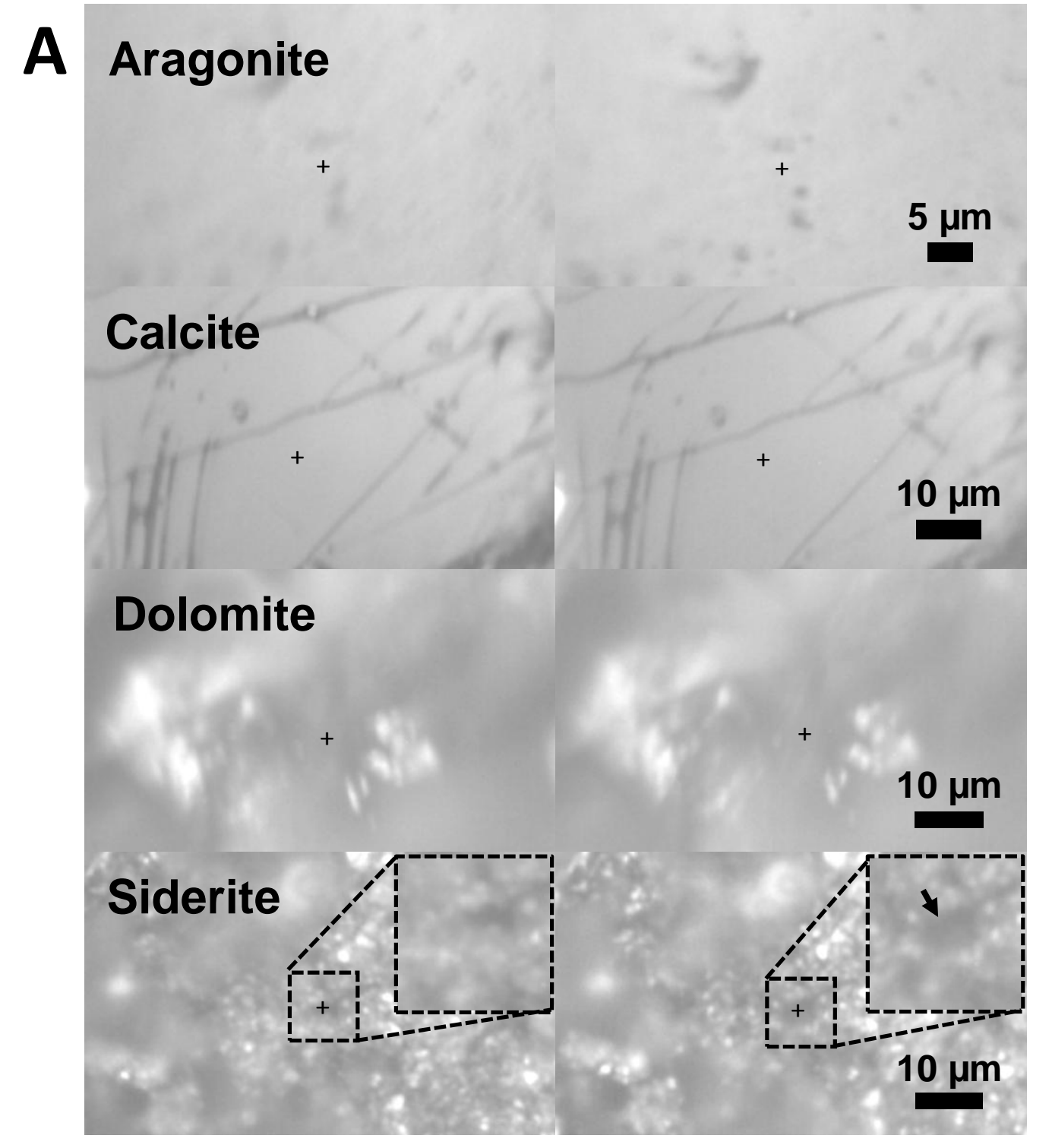

Before Irradiation After Irradiation

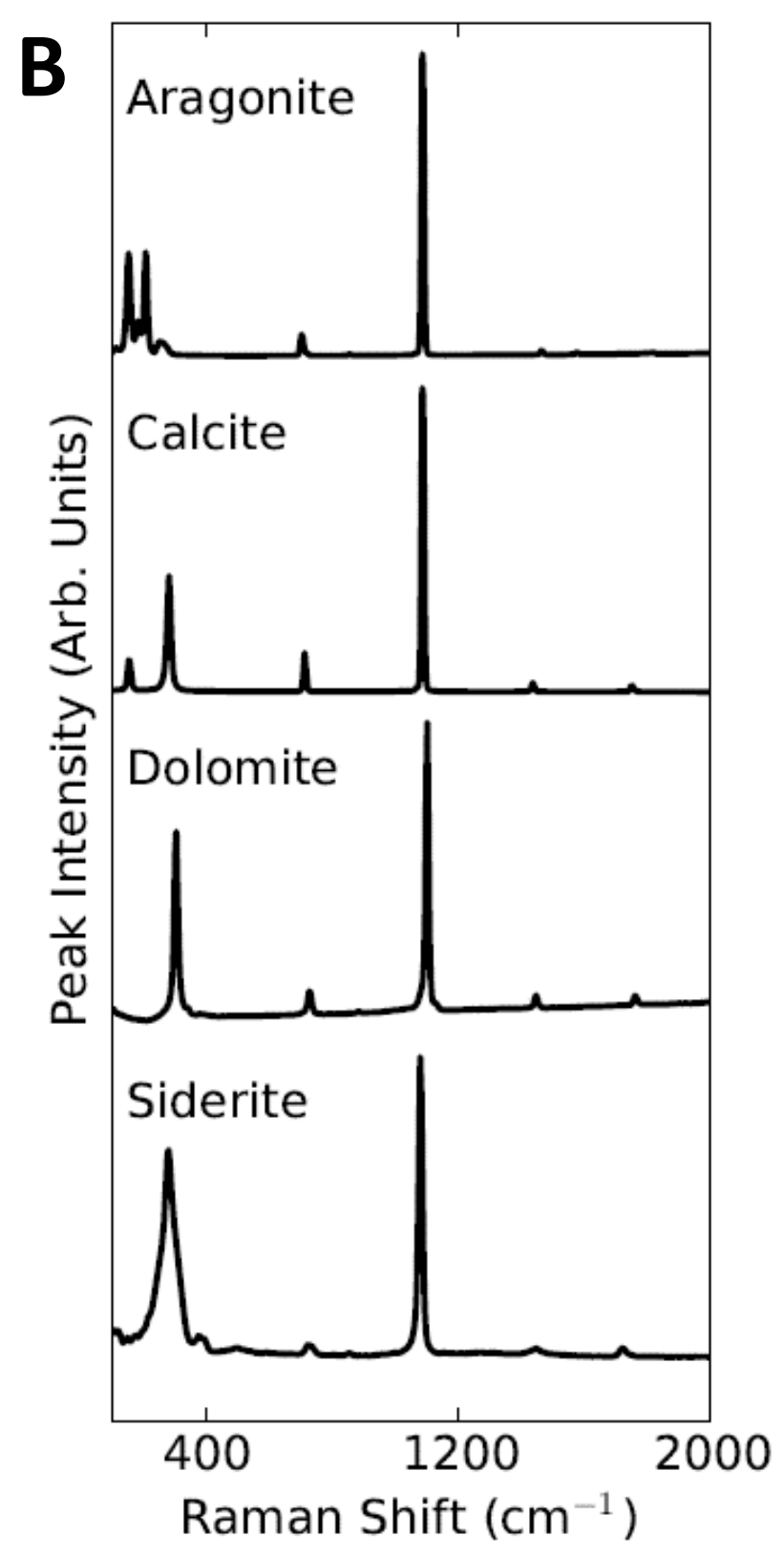


+ + Raw data

- Lorentzian + BWF

ज -2 Voigt

$\stackrel{=}{5}$

..- 2 Lorentzian

- 2 Gaussian

这

- 5 Lorentzian

$\frac{3}{4}$

ब



列

a

1000

1200

1400 


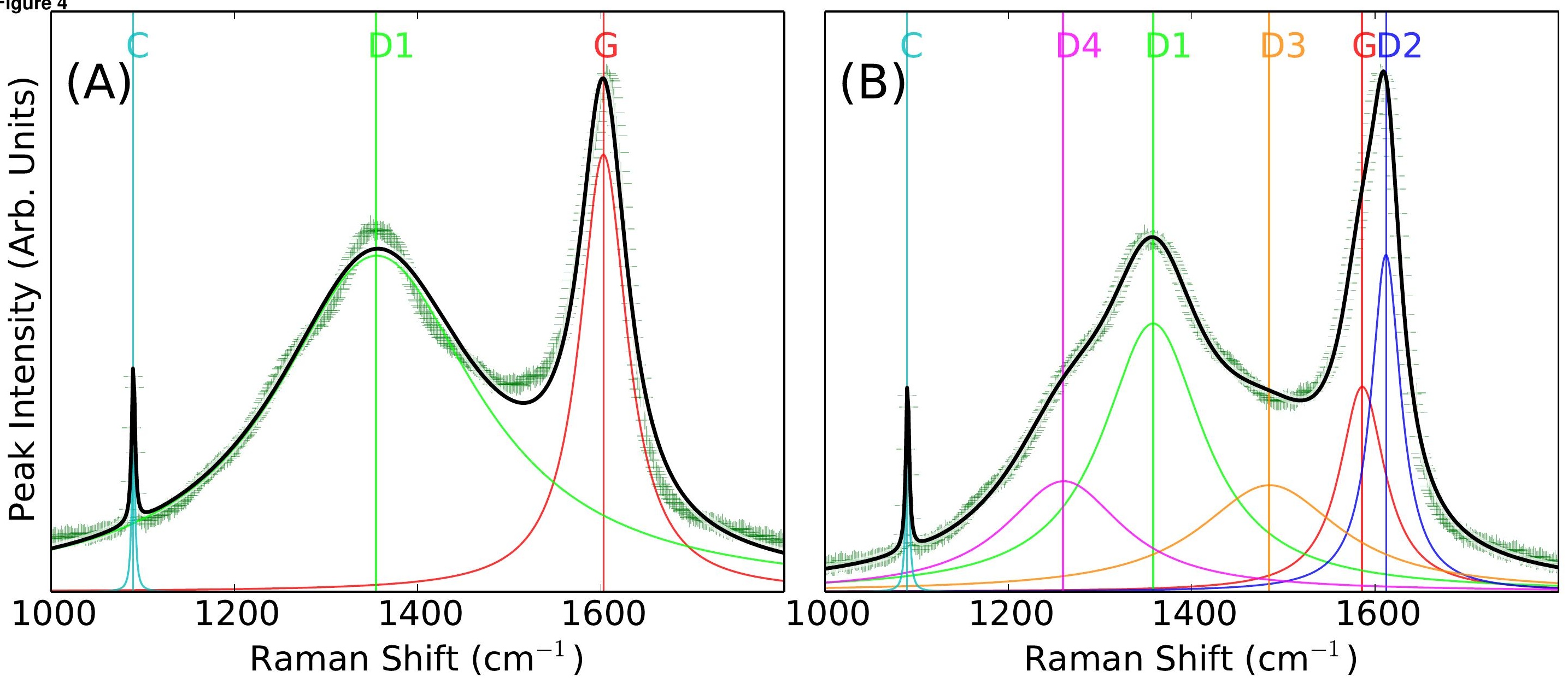




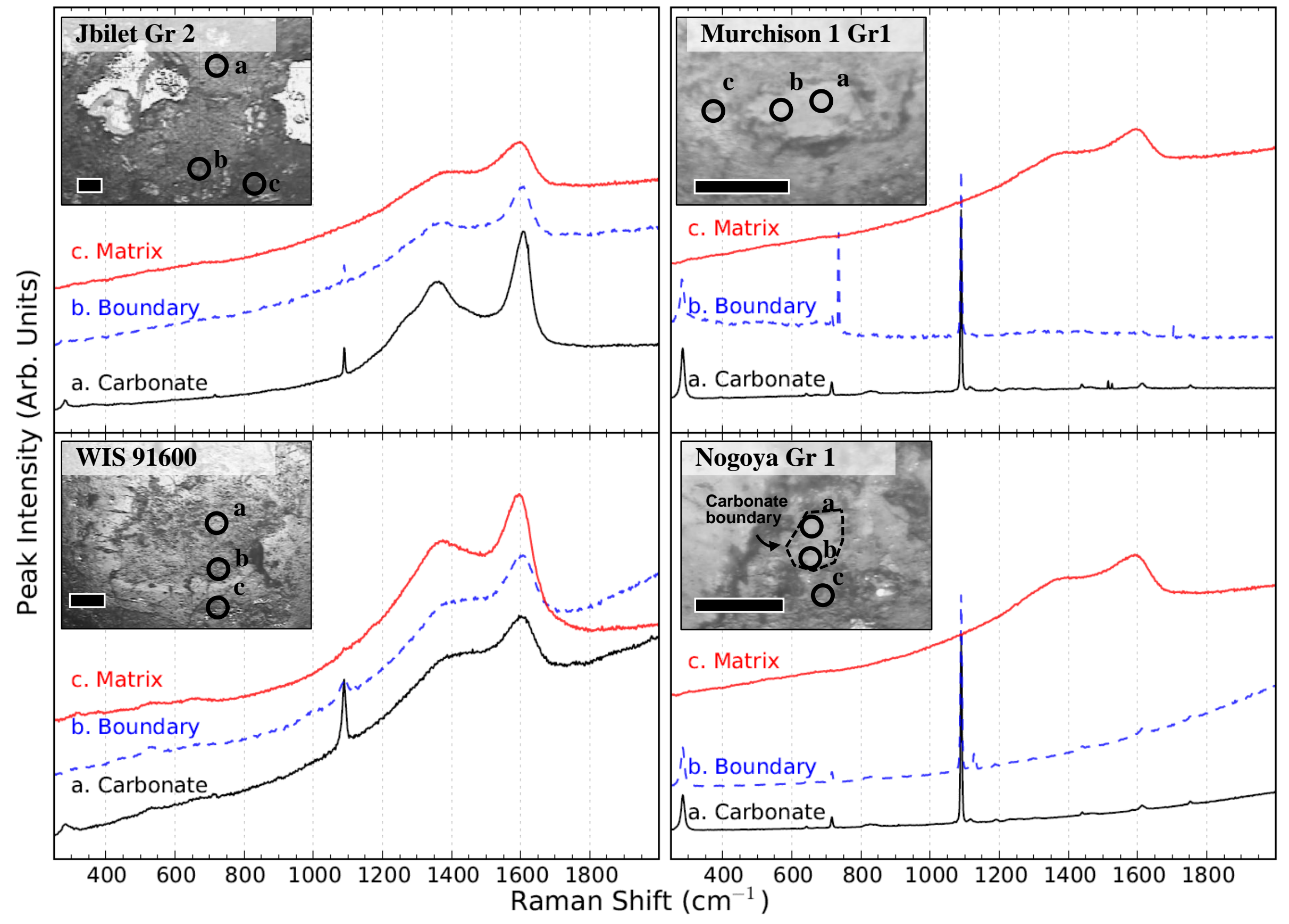



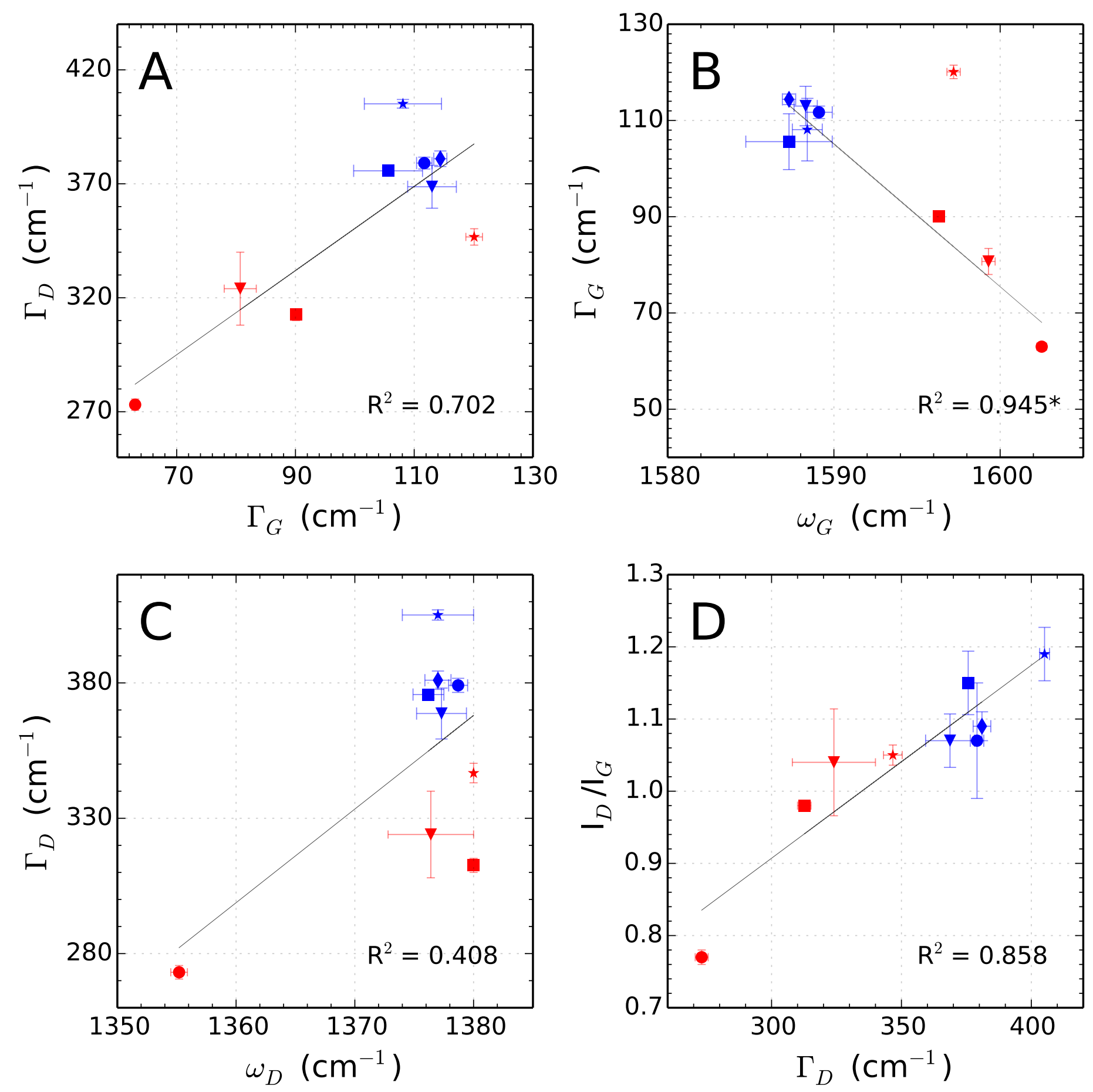
Eigturaßively represented by meteorites such as Yamato 86789

Ices

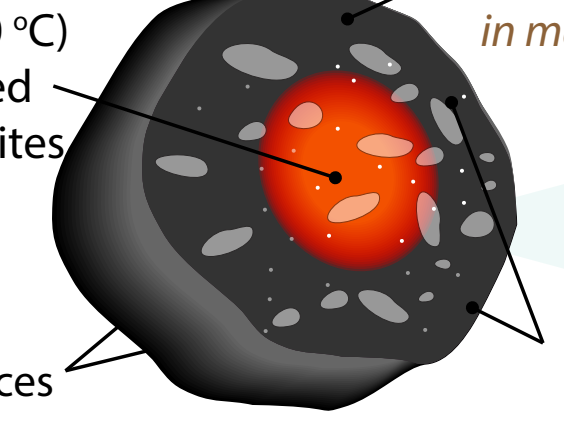

Low-grade

metamorphism

in the outer

region

represented

by meteorites such as Jbilet and Nogoya of carbonate

but not

favorable

for organics $\infty$ 0 activity

Reduce in

heat source from decay of radionuclides fluid is more

favorable

for organics \& carbonate

to coexist
(1) Metamorphic event induced by radioactive decay
2
Extensive aqueous alteration and precitation of OM barren carbonates
3
Localized heating triggered the precipitation of OM-bearing carbonates 